\title{
Interpretation of fast repetition rate (FRR) fluorescence: signatures of phytoplankton community structure versus physiological state
}

\author{
David J. Suggett ${ }^{1, *}$, C. Mark Moore ${ }^{2}$, Anna E. Hickman ${ }^{3}$, Richard J. Geider ${ }^{1}$ \\ ${ }^{1}$ Department of Biological Sciences, University of Essex, Colchester, Essex CO4 3SQ, UK \\ ${ }^{2}$ National Oceanography Centre, European Way, Southampton SO14 3ZH, UK \\ ${ }^{3}$ Proudman Oceanographic Laboratory, Joseph Proudman Building, 6 Brownlow Street, Liverpool L3 5DA, UK
}

ABSTRACT: Introduction of active chlorophyll a fluorescence protocols, in particular fast repetition rate (FRR) fluorometry, to oceanography and limnology $15 \mathrm{yr}$ ago has enabled rapid assessment of photosynthetic physiology in situ. The FRR protocol generates simultaneous measurements of Photosystem II (PSII) effective absorption cross sections (termed $\sigma_{\mathrm{PSII}}$ ) and photochemical efficiency (termed $F_{\mathrm{v}} / F_{\mathrm{m}}$ ). Both $F_{\mathrm{v}} / F_{\mathrm{m}}$ and $\sigma_{\text {PSII }}$ measurements have been utilised to examine the effects of physiological stress on the photosynthetic apparatus of phytoplankton in an ever growing number of fluorescence-based studies. However, it is now becoming clearer that in situ values of $F_{\mathrm{v}} / F_{\mathrm{m}}$ and $\sigma_{\mathrm{PSII}}$ also contain taxonomic information. Here, we present a synthesis of previously unpublished and published data, which show that $F_{\mathrm{v}} / F_{\mathrm{m}}$ and $\sigma_{\mathrm{PSII}}$ vary principally with broad-scale changes in community structure. These patterns observed in situ conform to trends observed in laboratory-grown cultures of a range of phytoplankton taxa. The magnitudes of variability in $F_{\mathrm{v}} / F_{\mathrm{m}}$ and $\sigma_{\mathrm{PSII}}$ driven by changes in phytoplankton community structure often exceed that induced by nutrient limitation (as determined from controlled nutrient addition experiments). An exception to this general trend occurs in high-nutrient, low-chlorophyll a (HNLC) regions, where strong phenotypic changes in $F_{\mathrm{v}} / F_{\mathrm{m}}$ and $\sigma_{\mathrm{PSII}}$ have been repeatedly demonstrated on relief of iron limitation. Overall, FRR fluorescence measurements of both $F_{\mathrm{v}} / F_{\mathrm{m}}$ and $\sigma_{\mathrm{PSII}}$ in natural populations represent a combination of the taxonomic 'signature' (values of $F_{\mathrm{v}} / F_{\mathrm{m}}$ and $\sigma_{\mathrm{PSII}}$ determined by the taxa present) within the phytoplankton community that is further modified according to the (photo-) physiological status. As such, fluorescence-based investigations of mixed populations must account for potential variations in phytoplankton community structure before interpretations of physiological status are made.

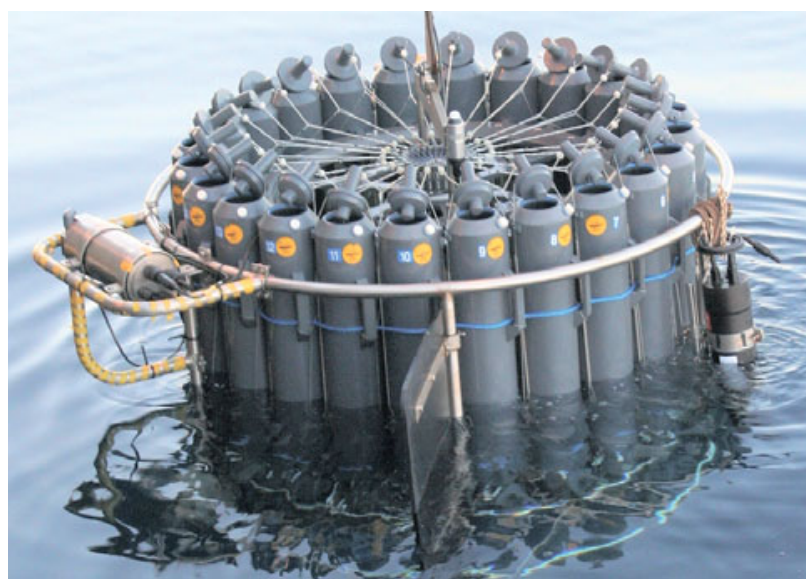

Fast Repetition Rate fluorometer (at left) attached to a CTD rosette sampler being deployed in the Celtic Sea.

Photo: Young-Nam Kim

KEY WORDS: Fast repetition rate - Fluorescence · PSII $\cdot$ Effective absorption cross section $\cdot$ Photochemical efficiency $\cdot$ Phytoplankton $\cdot$ Nutrient stress

Resale or republication not permitted without written consent of the publisher

\section{INTRODUCTION}

An important milestone for aquatic research was the introduction of active chlorophyll a fluorometry to oceanography and limnology 15 yr ago (Falkowski \& Raven 2007, Prášil et al. 2008). Technological and commercial development has since packaged various active fluorescence protocols into a number of plat- 
forms, from submersible profilers to bench-top imagers to aircraft remote-sensing light detection and ranging (LIDAR) platforms enabling its application across almost every field, from coral biology to ocean biogeochemistry (Prášil et al. 2008). As a direct result, active fluorometry has rapidly become an established tool by which scientists and managers evaluate the response of aquatic systems to environmental change.

Initial in situ studies immediately demonstrated the capabilities of active fluorescence for rapidly assessing the photosynthetic physiology of phytoplankton as they existed in nature (Kolber et al. 1990, Geider et al. 1993a, Greene et al. 1994). Conceptually, active chlorophyll a fluorescence measurements evaluate the efficiency by which absorbed light is utilised by photosynthesis: chlorophyll a fluorescence itself being a biophysical byproduct reflecting absorbed light not utilised for photochemistry by the oxygen evolving Photosystem II complex (PSII). Such measurements are strongly dependent on prior light exposure, and thus the PSII photochemical efficiency is at its highest (maximum) following a period of dark acclimation, i.e. when the primary acceptor molecules of PSII (quinones) are fully oxidised and ready to receive electrons. This maximum PSII photochemical efficiency typically decreases when autotrophs experience 'stressful' growth conditions, such as nutrient starvation or excessive light (Kolber et al. 1988, 1994, Geider et al. 1993b). It is this concept that has led to use of chlorophyll a fluorescence measurements for ascertaining the photosynthetic 'condition' of entire phytoplankton communities across large temporal (Suggett et al. 2006a) and spatial (Behrenfeld et al. 1996, Suzuki et al. 2002, Moore et al. 2005, 2006a,b, Suggett et al. 2006b) scales approaching those of oceanic ecosystems (Behrenfeld \& Kolber 1999, Behrenfeld et al. 2006, Suggett et al. 2006b).

Of key interest to oceanographers has been a specific form of active fluorometry termed fast repetition rate (FRR; Kolber et al. 1998) and analogous techniques, including fluorescence induction and relaxation (FIRe; Bibby et al. 2008, Suggett et al. 2008). These fluorometers enable the high fluorescence sensitivity required for low chlorophyll a oligotrophic waters. Moreover these protocols result in the majority of PSII reaction centres being closed within the timescale of a single photochemical turnover (ST) (Kolber et al. 1998), enabling simultaneous measurement of the maximum PSII effective absorption cross section, termed $\sigma_{\text {PSII }}$, and the maximum PSII photochemical efficiency, termed $F_{\mathrm{v}} / F_{\mathrm{m}}$. The PSII effective absorption, also referred to as the functional absorption cross section, describes the functional 'target area' of the lightharvesting antenna that is energetically coupled to the $\mathrm{O}_{2}$-evolving reaction centres (RCIIs) ( $\sigma_{\text {PSII }}$ Mauzerall \& Greenbaum 1989, Falkowski \& Raven 2007).
Achieving simultaneous measurements of $F_{\mathrm{v}} / F_{\mathrm{m}}$ and $\sigma_{\text {PSII }}$ has proved to be an important step in active fluorometry by enabling autonomous estimates of the photosynthetic electron transfer (PET) rate (Kolber \& Falkowski 1993). Under actinic light, both $F_{\mathrm{v}} / F_{\mathrm{m}}$ and $\sigma_{\text {PSII }}$ are modified according to how the absorbed light is utilised by PSII. Until the development of FRR, active fluorometry typically only measured $F_{\mathrm{v}} / F_{\mathrm{m}}$ and so had to rely on independent measurements of light absorption to calculate PET rates in absolute terms (Kromkamp \& Forster 2003, Johnsen \& Sakshaug 2007). The measurements of $\sigma_{\text {PSII }}$ also proved to be an additional advancement for active fluorometry, since this variable also appears to characterise an (eco-) physiological response to changes in environmental conditions (Greene et al. 1994, Kolber et al. 1994, Behrenfeld et al. 1996, Behrenfeld \& Kolber 1999, Sosik \& Olson 2002, Moore et al. 2006a,b, 2007, Suggett et al. 2006b, Six et al. 2008).

Substantial FRR fluorescence data sets now exist for phytoplankton from both laboratory-grown monocultures and natural communities. These data indicate that the biophysical characteristics of PSII, expressed as $F_{\mathrm{v}} / F_{\mathrm{m}}$ and $\sigma_{\mathrm{PSII}}$, contain a taxonomic 'signature', i.e. a unique identity, upon which is superimposed physiological variability (Suggett et al. 2004, Moore et al. 2005, 2006b, 2008, Fishwick et al. 2006). As such, FRR fluorescence measurements from natural communities cannot be interpreted on the basis of physiological stress alone (Prášil et al. 2008). Such a realisation is perhaps not surprising since light absorption is one of the key factors operated on by selective pressure during the evolution of phytoplankton taxa (Wood 1985, Glover et al. 1987, Stomp et al. 2007). As a result, the compliment and arrangement of pigments housed within the light-harvesting antennae are highly variable amongst phytoplankton groups (Lutz et al. 2001, MacIntyre et al. 2002, Johnsen \& Sakshaug 2007). Such fundamental differences in antenna structure between phytoplankton groups are expected to result in mechanistic differences in both PSII light-harvesting potential and the efficiency with which this absorbed light is utilised (see Lavergne \& Joliot 2000, Lutz et al. 2001).

Here, we present a synthesis of unpublished and previously published FRR fluorescence data collected from numerous laboratory-grown marine phytoplankton to demonstrate that FRR fluorescence measurements represent (eco-) physiological variability influenced by both phytoplankton community structure and physiological 'stress'. We also examine both unpublished and published FRR fluorescence data sets from (1) broad-scale environmental surveys and (2) nutrient-addition bioassay experiments to demonstrate conditions where and when FRR fluorescence measurements include important taxon-specific ecophysio- 
logical traits of in situ phytoplankton populations. Consequently, we illustrate the relative magnitude of variability in $F_{\mathrm{v}} / F_{\mathrm{m}}$ and $\sigma_{\mathrm{PSII}}$ within and between phytoplankton taxa, highlighting that care must be taken when using FRR fluorescence to assess physiological stress (principally nutrient stress) of natural phytoplankton populations. With these findings in mind, we briefly discuss current directions for FRR fluorometry.

\section{MATERIALS AND METHODS}

Common methodologies apply to both the unpublished and previously published data sets analysed here. We will briefly describe these methodologies; however, readers are referred to the original sources for full details.

FRR fluorescence. All FRR measurements were made using 'standard' protocols as described by Suggett et al. (2003, 2004) and Moore et al. (2005, 2006b). A Chelsea Instruments Fast ${ }^{\text {tracka }}$ FRR fluorometer was programmed to deliver ST saturation of PSII from 100 flashlets of $1.1 \mu \mathrm{s}$ at $1 \mu \mathrm{s}$ intervals. Induction curves were averaged over 160 to 320 individual sequences to minimize error. Fluorescence transients generated by the FRR were then fitted to the Kolber-PrasilFalkowski (KPF; Kolber et al. 1998) model to yield values of $F_{\mathrm{v}} / F_{\mathrm{m}}$ and $\sigma_{\mathrm{PSII}}$ (see Moore et al. 2006b). Importantly, the measured value of $\sigma_{\text {PSII }}$ will be weighted to the spectral quality of light used to induce the fluorescence transient. The Fast ${ }^{\text {tracka }}$ has LEDs with peak excitation at $478 \mathrm{~nm}$ and a relatively narrow band width $(25 \mathrm{~nm})$; therefore, all values of $\sigma_{\mathrm{PSII}}$ reported by this method are weighted to the blue region of the photosynthetically active radiation (PAR) spectrum and should strictly be quoted as $\sigma_{\text {PSII }}(\sim 47 \mathrm{~nm})$ (Moore et al. 2006b). Connectivity ( $\rho$ ) was not fixed at the time of fitting the KPF model (see Suggett et al. 2004). However, values for $\rho$ were always between ca. 0.2 and 0.4 (dimensionless), and extensive tests with subsets of the data indicated no sensitivity of our conclusions to assumptions about connectivity (not shown). Instrument non-linearity was corrected for at the time of curve fitting from fluorescence transients of chlorophyll a extracts following Laney \& Letelier (2008). Blanks were also collected from fluorescence induction recordings of filtrates for each sample as described in detail by Moore et al. (2006b) and Suggett et al (2006a).

Additional measurements. Additional information was required to interpret either field and/or laboratory FRR data. Methods for obtaining the PSII photosynthetic unit size (mol chl a:mol RCII), pigment concentrations, and excitation spectra for PSII fluorescence have been described previously (Suggett et al. 2004,
Moore et al. 2006b). Briefly, PSII photosynthetic unit sizes were determined from $\mathrm{O}_{2}$-flash yield measurements using a custom-built LED flash system (Suggett et al. 2003). Pigment concentrations were measured by high-performance liquid chromatography (HPLC) via identification and co-elution with pigment standards (see Leonardos \& Geider 2004, Moore et al. 2006b). Finally, PSII fluorescence excitation spectra (400 to $715 \mathrm{~nm}$ ) were measured with the monochromator on the detector set to $730 \mathrm{~nm}$ emission $\left(F_{730}\right)$ upon samples pre-treated with DCMU (Lutz et al. 2001, Suggett et al. 2004). Values for $F_{730}$ were normalized to values for $\sigma_{\text {PSII }}$ at $478 \mathrm{~nm}$, since this wavelength corresponded with the wavelength of peak excitation from the FRR fluorometer. As such, excitation spectra for PSII can be used to extrapolate measurements of the effective absorption measured by the FRR $\left(\sigma_{\text {PSII }}, 487 \mathrm{~nm}\right)$ to other wavelengths (see Suggett et al. 2007).

Data sets 1: algal cultures. The phytoplankton data set includes 38 species spanning 10 classes (Table 1). Most species were grown at either the University of Essex (UK) or Horn Point Laboratory (Maryland, USA), data is also included from algal cultures grown at Bar-Ilan University (Israel, Ilana Berman-Frank) and the Finnish Institute of Marine Research (Mika Raateoja) (Table 1). Cultures were grown under 1 or more growth photon flux density (PFD) and were maintained in batch or semibatch mode in nutrient replete media, as described previously (Raateoja et al. 2004, Suggett et al. 2004, Berman-Frank et al. 2007). Growth was performed under optimum temperatures and salinity, except where stated (Table 1). Cultures were maintained in exponential growth phase, as monitored using daily FRR fluorescence or haemocytometer cell counts, and sampled in triplicate from sequential cell generations.

In addition to our culture data, we have also included published FRR data for $F_{\mathrm{v}} / F_{\mathrm{m}}$ and $\sigma_{\mathrm{PSII}}$ digitised from Prochlorococcus experiments of Steglich et al. (2001) and Bruyant et al. (2005) (Table 1). The digitised FRR measurements do not appear to account for cases of instrument non-linearity or sample blanks; however, the latter are probably unimportant where chlorophyll a concentrations exceed 1 to $10 \mathrm{mg} \mathrm{m}^{-3}$ (Suggett et al. 2006a), i.e. concentrations substantially below those for the Prochlorococcus cultures.

Data sets 2: field sampling. Primary field data sources were from selected cruises spanning a range of hydrographic regimes including seasonally stratified shelf sea (JR98; Moore et al. 2006b), Atlantic open ocean (AMT 15 and 17; Hickman \& Suggett unpubl. data; Meteor 60, Moore et al. 2006a, 2008) and southern Indian ocean (CROZEX; Moore et al. 2007). The field data thus traversed large environmental and taxonomic gradients and yet are known to have consistently applied the same FRR techniques and data analysis throughout. 
Table 1. Summary information for cultured marine phytoplankton examined using fast repetition rate (FRR) fluorescence. Culture reference banks are CCMP (Provasoli-Guillard National Center for Culture of Marine Phytoplankton Boothbay Harbour, Maine, USA), CCAP (Culture Collection of Algae and Protozoa, Dunstaffnage Marine Laboratory, Scotland, UK), PCC (Plymouth Culture Collection of Marine Algae, Marine Biological Association, Plymouth, UK), Choptank Isolates (Choptank River isolated by Alan Lewitus and maintained at Horn Point Laboratory, MD, USA) and Woods Hole (WH) isolate (Woods Hole Oceanographic Institute, MA, USA, by J. Waterbury). Cyanobacterial strains KAC and HEM are Baltic Sea isolates. All algae were grown under steady-state, nutrient-replete conditions as described by Suggett et al. $(2003,2004)$. All species were grown under 1 or more irradiances and at optimum growth temperatures $\left(15\right.$ to $20^{\circ} \mathrm{C}$ ) and salinity (30 to $35 \mathrm{PSU}$ ), except where strains were grown at $5^{\circ} \mathrm{C}$ and 15 to 25 PSU $\left({ }^{*}\right)$. All cultures were maintained in media at an N:P of 15 to 16 , except where strains were grown at an N:P of 5 , 15 or $45\left({ }^{* *}\right)$. Steady-state FRR data provided by I. Berman-Frank for Trichodesmium spp., Cyanothece spp. and Anabaena spp. were from various iron concentrations, temperatures and salinities (refer to Berman-Frank et al. 2007)

\begin{tabular}{|c|c|c|c|}
\hline Algal class & Species & Culture ID & $\begin{array}{l}\text { Methods for cell growth } \\
\text { and/or FRR data source }\end{array}$ \\
\hline \multirow[t]{10}{*}{ Diatom } & Chaetoceros muelleri & CCAP1010/3 & Leonardos \& Geider (2004) ${ }^{* *}$ \\
\hline & Coscinodiscus wallensi & PCC621 & Estevez-Blanco \& Suggett unpubl. data \\
\hline & Skeletonema costatum & CCMP1332 & Le Floc'H \& Suggett unpubl data* \\
\hline & Phaeodactylum cornutum & CCMP 1327 & Estevez-Blanco \& Suggett unpubl. data \\
\hline & Thalassiosira weissflogii & CCMP1047 & Suggett et al. $(2003,2004)$ \\
\hline & Thalassiosira weissflogii & CCMP1336 & Estevez-Blanco \& Suggett unpubl. data \\
\hline & Thalassiosira pseudonana & CCMP1335 & Estevez-Blanco \& Suggett unpubl. data \\
\hline & Thalassiosira puncitgera & PCC623 & Estevez-Blanco \& Suggett unpubl. data \\
\hline & Thalassiosira minima & CCAP1085/8 & Estevez-Blanco \& Suggett unpubl. data \\
\hline & Thalassiosira eccentrica & CCAP1085/6 & Estevez-Blanco \& Suggett unpubl. data \\
\hline \multirow[t]{3}{*}{ Dinoflagellate } & Prorocentrum minimum & CCAP1136/14 & Le Floc'H \& Suggett unpubl. data* \\
\hline & Prorocentrum minimum & Choptank & Suggett et al. (2004) \\
\hline & Symbiodinium microadriaticum & CCMP1633 & Hennige \& Suggett unpubl. data \\
\hline \multirow[t]{5}{*}{ Prymnesiophyte } & Coccolithus pelagicus & PCC182 & Estevez-Blanco \& Suggett unpubl. data \\
\hline & Emiliania huxleyi & PCC/B92 & Suggett et al. (2007) \\
\hline & Emiliania huxleyi & PCC/B11 & Suggett et al. (2007) \\
\hline & Isochrysis galbana & CCMP1323 & Estevez-Blanco \& Suggett unpubl. data \\
\hline & Prymnesium parvum & PCC94 & Estevez-Blanco \& Suggett unpubl. data \\
\hline \multirow[t]{3}{*}{ Chlorophyte } & Dunaliella tertiolecta & CCAP 19/6B & Suggett et al. (2003) \\
\hline & Dunaliella tertiolecta & CCMP 1320 & Suggett et al. $(2003,2004)$ \\
\hline & Nannochloris atomus & CCMP509 & Suggett et al. (2003) \\
\hline \multirow[t]{3}{*}{ Cryptophyte } & Rhodomonas salina & CCAP 978/27 & Le Floc'H \& Suggett unpubl. data* \\
\hline & Rhodomonas salina & CCMP1319 & Estevez-Blanco \& Suggett unpubl. data \\
\hline & Storeatula major & Choptank & Suggett et al. (2004) \\
\hline \multirow[t]{8}{*}{ Cyanophyte } & Aphanizomenon sp. & KAC15 & Raateoja et al. (2004) \\
\hline & Nodularia spumigena & HEM & Raateoja et al. (2004) \\
\hline & Synechococcus sp. & CCMP837 & Suggett unpubl. data* \\
\hline & Synechococcus sp. & WH 7803 & Suggett et al. (2004) \\
\hline & Trichodesmium sp. & IMS101 & Berman-Frank et al. (2007) \\
\hline & Katagnymene sp. & WH isolate & Berman-Frank unpubl. data \\
\hline & Cyanothece sp. & WH 8904 & Berman-Frank et al. (2007) \\
\hline & Anabaena flos aqua & UTEX 2557 & Berman-Frank et al. (2007) \\
\hline \multirow[t]{2}{*}{ Prochlorophyte } & Prochlorococcus marinus & PCC 9511 & Bruyant et al (2005) \\
\hline & Prochlorococcus marinus & CCMP 1375 & Steglich et al. (2001) \\
\hline \multirow[t]{2}{*}{ Pelagophyte } & Aureococcus anophagefferens & CCMP1790 & Suggett et al. (2004) \\
\hline & Pelagococcus subviridis & CCMP1429 & Estevez-Blanco \& Suggett unpubl. data \\
\hline Prasinophyte & Pycnococcus provasolii & CCMP 1203 & Suggett et al. (2004) \\
\hline Rhodophyte & Porphyridium cruentum & Choptank & Suggett et al. (2004) \\
\hline
\end{tabular}

Full details of all cruise data synthesised are provided in Table 2. FRR fluorescence measurements were performed on discrete water samples drawn from Niskin bottles at various depths within the upper euphotic zone or from the ships' underway surface seawater supply. Water samples were collected pre-dawn (AMT 15, 17, JR98, Meteor 60) or were dark adapted for 45 to 60 min to ensure full dark adaptation. Nutrient perturbation experiments were carried out during CROZEX,
Meteor 60 and AMT 17. FRR protocols for AMT 15 and 17 followed those of Moore et al. (2006b), whilst nutrient perturbation protocols for AMT 17 followed those of Moore et al. (2006a, 2008).

Several additional field data sets were digitised from published sources for comparative purposes (Table 2). Values were extracted from continuous data sets corresponding to night-time or a PAR of zero to minimize the influence of reversible fluorescence quenching. 
Table 2. Summary of re-examined field data sets where FRR fluorescence was used to yield values of PSII photochemical efficiency $\left(F_{\mathrm{v}} / F_{\mathrm{m}}\right.$, dimensionless $)$ and effective absorption cross section $\left(\sigma_{\mathrm{PSII}}, \AA^{2}\right.$ quanta $\left.^{-1}\right)$. Previously unpublished data provided by Ondrej Prášil from nighttime vertical FRR casts was binned into 10 depths in the upper $200 \mathrm{~m}$. Similarly, data from Anna Hickman and David Suggett were from dark-adapted measurements upon discrete water samples collected pre-dawn using Niskin bottles (see Suggett et al. 2006b)

\begin{tabular}{|c|c|c|c|c|}
\hline Cruise & Geographical region & Location & Comments & Data set \\
\hline IronEx II & Eastern Equatorial Pacific & $3.5^{\circ} \mathrm{S}, 105^{\circ} \mathrm{W}$ & Surface water only & Behrenfeld et al. (1996) \\
\hline SOIREE & $\begin{array}{l}\text { Indian sector; south of the } \\
\text { Antarctic Polar Front (APF) }\end{array}$ & $61^{\circ} \mathrm{S}, 141^{\circ} \mathrm{E}$ & $\begin{array}{l}\text { Depth integrated; } \\
\text { binned to } F_{\mathrm{v}} / F_{\mathrm{m}} \text { intervals }\end{array}$ & Boyd \& Abraham (2001) \\
\hline RR09 & Polar Front-Ross Sea (N to $\mathrm{S}$ ) & $50-78^{\circ} \mathrm{S}, 165^{\circ} \mathrm{E}-165^{\circ} \mathrm{W}$ & Mean in upper $40 \mathrm{~m}$ & Sosik \& Olson (2002) \\
\hline \multirow[t]{2}{*}{ KH-99-3 } & $\begin{array}{l}\text { Trans-Pacific (E to W, } \\
\text { sub-Arctic) }\end{array}$ & $45-55^{\circ} \mathrm{N}, 155^{\circ} \mathrm{E}-135^{\circ} \mathrm{W}$ & Surface water only & Suzuki et al. (2002) \\
\hline & $\begin{array}{l}\text { Mertz Polynya region of East } \\
\text { Antarctica }\end{array}$ & $64-67^{\circ} \mathrm{S}, 140-150^{\circ} \mathrm{E}$ & $\begin{array}{l}10-20 \mathrm{~m} \text { and } 45-55 \mathrm{~m} \\
\text { depth bins }\end{array}$ & Vaillancourt et al. (2003) \\
\hline \multirow[t]{3}{*}{ FISHES } & $\begin{array}{l}\text { N. Atlantic (Iceland Basin- } \\
\text { Rockall Trough) }\end{array}$ & $56-66^{\circ} \mathrm{N}, 0-30^{\circ} \mathrm{W}$ & $\begin{array}{l}\text { Mean value in surface } \\
\text { mixed layer }\end{array}$ & Moore et al. (2005) \\
\hline & Ría de Vigo, NW Spain & $42^{\circ} 20^{\prime} \mathrm{N}, 8^{\circ} 70^{\prime} \mathrm{W}$ & Two depths; seasonal & Cermeño et al. (2005) \\
\hline & $\begin{array}{c}\text { SW coastal Africa (Cape } \\
\text { Town to Orange River) }\end{array}$ & $33-29^{\circ} \mathrm{S}, 15-18^{\circ} \mathrm{W}$ & $\begin{array}{l}\text { Depth of maximum in the } \\
\text { enclosed chamber }\end{array}$ & Fishwick et al. (2006) \\
\hline JR98 & $\begin{array}{l}\text { N. Atlantic (UK-Ireland } \\
\text { shelf sea) }\end{array}$ & $48-53^{\circ} \mathrm{N}, 5-10^{\circ} \mathrm{W}$ & $\begin{array}{l}\text { Two depths, surface and } \\
\text { thermocline }\end{array}$ & Moore et al. (2006b) \\
\hline CROZEX & $\begin{array}{l}\text { S. Atlantic (Polar-Frontal } \\
\text { zone of Southern Ocean) }\end{array}$ & $44-49^{\circ} \mathrm{S}, 49-56^{\circ} \mathrm{E}$ & $\begin{array}{l}\text { Two depths, surface and } \\
\text { thermocline }\end{array}$ & Moore et al. (2007) \\
\hline Meteor 60 & $\begin{array}{l}\text { Trans-Atlantic (W to E, } \\
\text { subtropical) }\end{array}$ & $18-36^{\circ} \mathrm{N}, 66-24^{\circ} \mathrm{W}$ & Surface water only & Moore et al. (2008) \\
\hline AMT 15 & Trans-Atlantic (N to $\mathrm{S}$ ) & $48^{\circ} \mathrm{N}-40^{\circ} \mathrm{S}, 25^{\circ} \mathrm{W}-10^{\circ} \mathrm{E}$ & 10 depths, upper $200 \mathrm{~m}$ & Hickman unpubl. data \\
\hline BIOSOPE & Subtropical Pacific & $31-34^{\circ} \mathrm{S}, 91-74^{\circ} \mathrm{W}$ & 10 depths, upper $200 \mathrm{~m}$ & Prášil unpubl. data \\
\hline AMT 17 & Trans-Atlantic (N to $\mathrm{S}$ ) & $48^{\circ} \mathrm{N}-35^{\circ} \mathrm{S}, 38^{\circ} \mathrm{W}-13^{\circ} \mathrm{E}$ & 10 depths, upper $200 \mathrm{~m}$ & Suggett unpubl. data \\
\hline
\end{tabular}

Again, it should be noted that these FRR data sets do not always appear to account for cases of non-linearity or sample blanks. The majority of these data sets employed a Chelsea Instruments FRR Fast ${ }^{\text {tracka }}$, with excitation set to $478 \mathrm{~nm}_{i}$ consequently, $\sigma_{\mathrm{PSII}}$ values reported here also strictly correspond to this wavelength, i.e. $\sigma_{\text {PSII }}(478 \mathrm{~nm})$. However, we also include data collected using an earlier 'prototype' variable fluorometer with an alternative excitation source (Kolber et al. 1988, 1994, Behrenfeld et al. 1996). Specifically, in this case, cut-off filters were used to isolate excitation by a xenon lamp between ca. 490 and $550 \mathrm{~nm}$ (Kolber \& Falkowski 1993), and so peak excitation is broader and slightly more shifted to 'green' than that employed by the Fast ${ }^{\text {tracka }}$. We consider how these alternative wavebands of excitation potentially affect the interpretation of $\sigma_{\mathrm{PSII}}$ and $F_{\mathrm{v}} / F_{\mathrm{m}}$ values in response to changes in taxa and growth environment in later sections. Hereafter, when considering direct measurements with a $478 \mathrm{~nm}$ excitation source, we use the notation $\sigma_{\mathrm{PSII}}(478)$ to indicate the corresponding functional absorption cross section (Moore et al. 2006b). In contrast, the more general discussions of the ecological/evolutionary context behind functional antenna size will contain the implicit assumption that phytoplankton absorption must be considered in the context of the wavelength regime of interest (i.e. the in situ spectral growth irradiance).

\section{RESULTS AND DISCUSSION}

\section{FRR fluorescence under unbalanced versus balanced growth}

In order to examine taxonomic effects we will first consider how environment, in terms of growth rate, determines FRR-based measurements. Microalgae grown under batch and continuous culture approaches demonstrate the effect of unbalanced versus balanced growth upon PSII fluorescence characteristics (e.g. Fig. 1). Typically, in batch cultures, cells exhibit a constant value of $F_{\mathrm{v}} / F_{\mathrm{m}}$ and $\sigma_{\mathrm{PSII}}$ (478) during logarithmic growth. However, a gradual decrease of $F_{\mathrm{v}} / F_{\mathrm{m}}$ and increase of $\sigma_{\mathrm{PSII}}(478)$ is observed once nutrient availability decreases relative to cellular demand for photosynthesis and so the growth rate inevitably declines (summarized by Parkhill et al. 2001). Growth rates and cellular physiology are thus not in balance with the nutrient supply. Inverse relations between $F_{\mathrm{v}} / F_{\mathrm{m}}$ and $\sigma_{\text {PSII }}$ are observed when PSII function becomes compromised by nutrient starvation (Kolber et al. 1988, Geider et al. 1993b, Steglich et al. 2001) or photoinhibition by visible or UV radiation (Vassiliev et al. 1995, Ragni et al. 2008). Such a decline of $F_{\mathrm{v}} / F_{\mathrm{m}}$ in response to stress can be interpreted to indicate a decline in the proportion of RCIIs that are functional: when the pool of functional and damaged RCIIs shares a common 


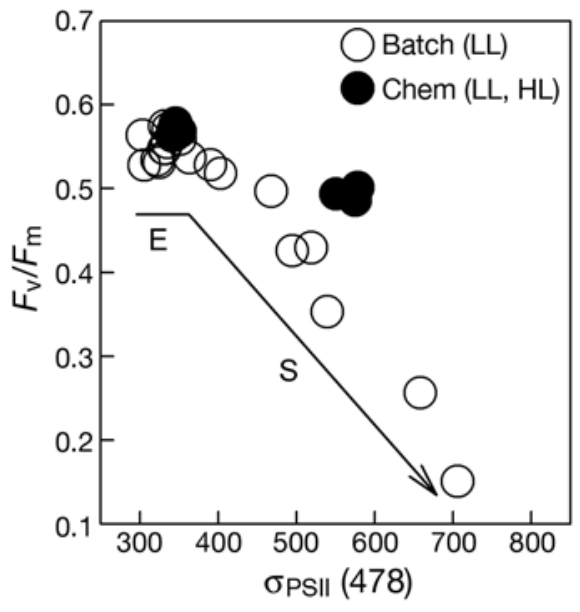

Fig. 1. Fast repetition rate (FRR) measurements of the maximum Photosystem II (PSII) photochemical efficiency $\left(F_{\mathrm{v}} / F_{\mathrm{m}}\right.$ dimensionless) and effective absorption cross section $\left(\sigma_{\mathrm{PSII}}\right.$ (478), $\AA^{2}$ quanta $^{-1}$ ) for the diatom Chaetoceros muelleri when grown in either batch- or chemostat-culture modes (see Table 1). In batch mode (O) nutrients were not replenished post-inoculation and values of $F_{\mathrm{v}} / F_{\mathrm{m}}$ and $\sigma_{\mathrm{PSII}}$ were recorded for cells growing at a single light intensity $(50 \mu \mathrm{mol}$ photons $\mathrm{m}^{-2} \mathrm{~s}^{-1}$ ) through exponential (E) and stationary (S) phases. Each data point represents measurements made on consecutive days; $\mathrm{E}$ and $\mathrm{S}$ phases were identified by simultaneous daily quantification of cell number (Leonardos \& Geider 2004). Values of $F_{\mathrm{v}} / F_{\mathrm{m}}$ and $\sigma_{\mathrm{PSII}}$ shown are the means from triplicate cultures. In chemostat mode $(\bullet)$ nutrients were replenished continuously and values of $F_{\mathrm{v}} / F_{\mathrm{m}}$ and $\sigma_{\mathrm{PSII}}$ were also recorded daily. Cultures were maintained under lowlight (LL, $50 \mu \mathrm{mol}$ photons $\mathrm{m}^{-2} \mathrm{~s}^{-1}$, growth rate $[\mu]=0.3 \mathrm{~d}^{-1}$ ) and high-light (HL, $700 \mu \mathrm{mol}$ photons $\mathrm{m}^{-2} \mathrm{~s}^{-1}, \mu=0.6 \mathrm{~d}^{-1}$ ) conditions. Both LL and HL data clusters consist of 3 data points, each representing a chemostat delivered with a different

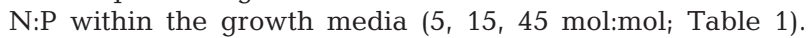
Here, values of $F_{\mathrm{v}} / F_{\mathrm{m}}$ and $\sigma_{\mathrm{PSII}}$ are the means from 15 to 22 consecutive days in steady-state growth

light-harvesting antenna, a decrease in the proportion of RCIIs that are functional (i.e. a decrease in $F_{\mathrm{v}} / F_{\mathrm{m}}$ ) is accompanied by an increase in the effective cross section, $\sigma_{\text {PSII }}$ (Greene et al. 1992, Vassiliev et al. 1995).

Cells in stationary-phase batch cultures, in which there is an abrupt exhaustion of nutrients, experience nutrient starvation. As such, batch cultures may provide a good model for the termination of a bloom by nutrient limitation in nature. However, under conditions of chronic nutrient limitation, regeneration of nutrients by heterotrophs can provide a continuous supply of nutrients. In the subtropical gyres, for example, there may be a high turnover of very small pools of dissolved nutrients due to a near balance between uptake of nutrients by phytoplankton and regeneration of nutrients by heterotrophs. In contrast to the batch approach, chemostat cultures continuously supply nutrients and the growth rate is strictly determined by the dilution rate, i.e. the rate of nutrient supply. Some chemostat studies have observed decreased val- ues of $F_{\mathrm{v}} / F_{\mathrm{m}}$ and increased values of $\sigma_{\mathrm{PSII}}$ as the growth rate is lowered (Kolber et al. 1988). However, such a trend is not the rule (Cullen et al. 1992, Parkhill et al. 2001). A continuous supply of nutrients eventually appears to enable cells to acclimate to chronic nutrient limitation. As a result, acclimation of the photosynthetic apparatus may alleviate or reduce the effects of nutrient limitation on $F_{\mathrm{v}} / F_{\mathrm{m}}$ and $\sigma_{\mathrm{PSII}}$. For example, although measured using an alternative active fluorescence technique, continuous culture studies have demonstrated little sensitivity of $F_{\mathrm{v}} / F_{\mathrm{m}}$ to the nutrientlimited, steady-state growth rate (Parkhill et al. 2001, Price 2005).

Insensitivity of $F_{\mathrm{v}} / F_{\mathrm{m}}$ and $\sigma_{\mathrm{PSII}}$ (478) to nutrientlimited growth conditions is also observed in FRR data collected during chemostat experiments of the diatom Chaetoceros muelleri (Fig. 1). Here, high light grown cells were allowed to grow at a higher dilution (growth) rate than were low light grown cells (Leonardos \& Geider 2004). Lower values of $F_{\mathrm{v}} / F_{\mathrm{m}}$ were not observed at the lower growth rates, but for cells grown under higher growth PFDs (at the higher growth rate). Therefore, these data indicate that the change in light availability outweighed any potential influence of nutrient limitation upon PSII functioning. In this experiment, cultures were also grown over a range of $\mathrm{N}$ :P concentrations for these same high-light, high-growth rate and low-light, low-growth rate conditions. However, values of $F_{\mathrm{v}} / F_{\mathrm{m}}$ and $\sigma_{\mathrm{PSII}}$ (478) did not vary between N:P treatments (Fig. 1, see legend). In other words, FRR fluorescence measurements were also insensitive to adjustments to the nutrient ratio supplied (N:P) as long as the dilution rate was held constant. Thus, it appears that the overall functional capacity of the fully acclimated PSII pool is insensitive to the N:P supply ratio, despite the latter controlling the biomass that can be achieved (Geider et al. 1993b).

\section{Taxonomic-dependence of $F_{\mathrm{v}} / F_{\mathrm{m}}$ and $\sigma_{\mathrm{PSII}}$}

Under nutrient-replete growth conditions values of $F_{\mathrm{v}} / F_{\mathrm{m}}$ are known to vary systematically amongst algal taxa (Koblížek et al. 2001, Suggett et al. 2003, Yentsch et al. 2004). The highest recorded FRR-based ST values of $F_{\mathrm{v}} / F_{\mathrm{m}}$ are between ca. 0.65 and 0.70 and were measured for chlorophytes and diatoms (e.g. Chlamydomonas reinhardtii and Scenedesmus quadricauda [Koblížek et al. 2001] and Thalassiosia weissflogii [Fig. 2A, see also Yentsch et al. 2004]). However, values for $F_{\mathrm{v}} / F_{\mathrm{m}}$ can be as low as 0.3 to 0.4 for the smallest (pico-) eukaryotes, such as the pelagophyte Aureococcus anophagefferens, the prasinopohyte Pycnococcus provasolii, and the rhodophyte Porphyridium cruentum (Fig. 2A). Values of $F_{\mathrm{v}} / F_{\mathrm{m}}$ for cyanobacteria are typi- 

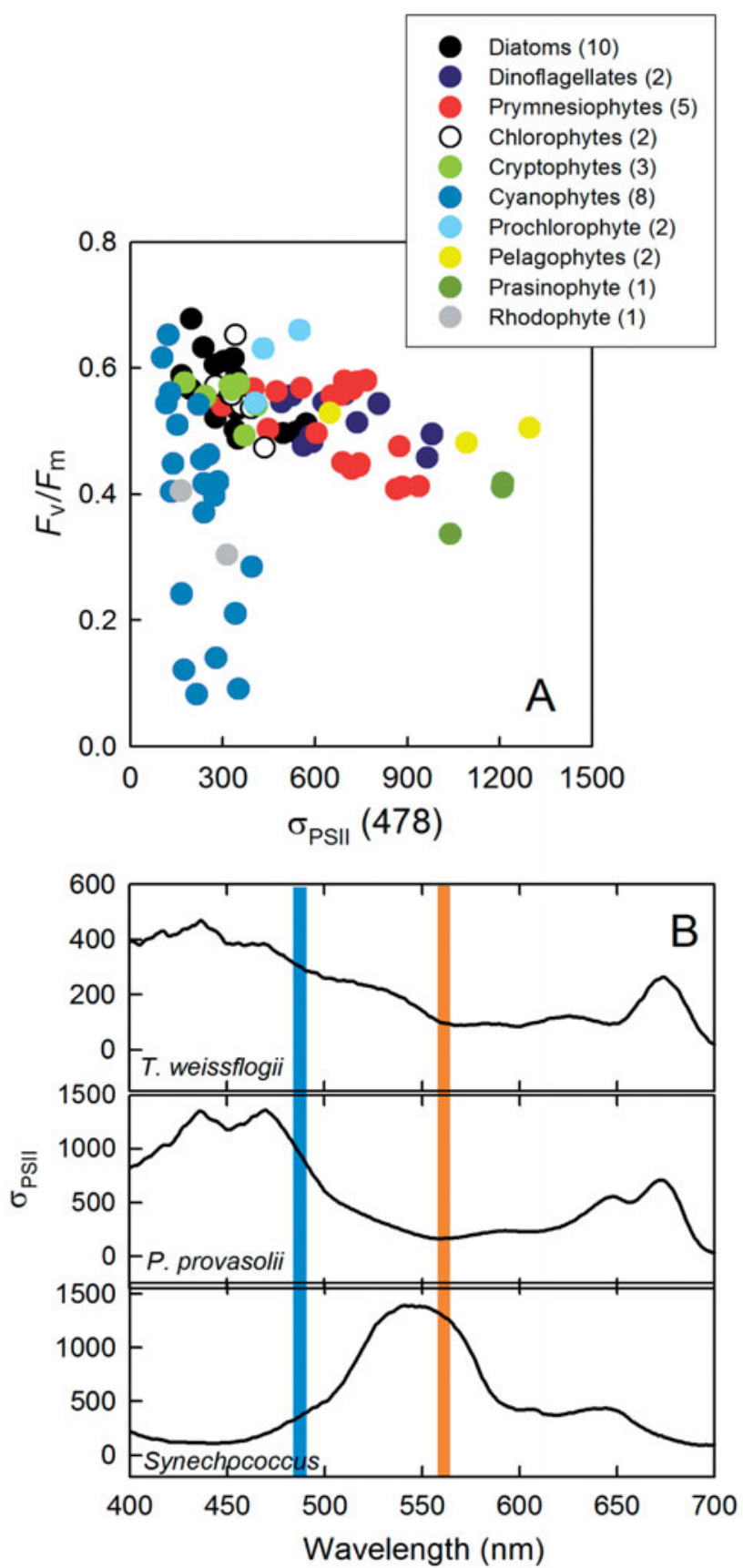

Fig. 2. (A) Values of the maximum PSII photochemical efficiency $\left(F_{\mathrm{v}} / F_{\mathrm{m}}\right.$, dimensionless) and effective absorption cross section $\left(\sigma_{\text {PSII }}(478), \AA^{2}\right.$ quanta $^{-1}$ ) measured from FRR fluorometry for various species of prokaryotic and eukaryotic marine phytoplankton (see Table 1 for a full list). Regressions for the phycobilisome and chlorophyll-xanthophyll light-harvesting complex $(\mathrm{LHC})$ 'trajectories' are $F_{\mathrm{v}} / F_{\mathrm{m}}=-0.0011 \times \sigma_{\mathrm{PSII}}(478)+0.621\left(\mathrm{r}^{2}=\right.$ $0.322, \mathrm{n}=23)$ and $F_{\mathrm{v}} / F_{\mathrm{m}}=-0.0002 \times \sigma_{\mathrm{PSII}}(478)+0.618\left(\mathrm{r}^{2}=0.405\right.$, $\mathrm{n}=79$ ), respectively. Species data have been pooled into phytoplankton classes indicated by different symbols. (B) Examples of $\sigma_{\mathrm{PSI}}$-excitation spectra recorded for a diatom (Thalassiosira weissfloggii CCMP1047), prasinophyte (Pycnococcus provasolii CCMP 1203) and cyanophyte (Synechococcus sp. WH7803). Solid lines indicate values of $\sigma_{\mathrm{PSII}}$ expected when exciting PSII with blue light $(478 \mathrm{~nm})$ and orange light $(560 \mathrm{~nm})$ cally between 0.1 and 0.4 (Koblížek et al. 2001, see also Campbell et al. 1998), but values in excess of 0.60 to 0.65 have been measured for some species of nitrogenfixing cyanobacteria (e.g. in the genera Cyanotheca and Anabaena; Berman-Frank et al. 2007; see Fig. 2). Thus, despite early suggestions (Kolber et al. 1988, Geider et al. 1993a, Kolber \& Falkowski 1993), a common maximum value for $F_{\mathrm{v}} / F_{\mathrm{m}}$ cannot be assigned to all algae (see discussion by Suggett et al. 2004).

As with $F_{\mathrm{v}} / F_{\mathrm{m}}$, FRR-based values of $\sigma_{\mathrm{PSII}}$ appear to vary across algal taxa (Koblížek et al. 2001, Suggett et al. 2004). In fact, plotting corresponding values of $F_{\mathrm{v}} / F_{\mathrm{m}}$ and $\sigma_{\mathrm{PSII}}(478)$ reveals that the 2 variables negatively co-vary across a wide range of algal classes (Fig. 2A). These data sets include species that have been grown at $>1$ PFD and in both chemostat and batch culture modes (Table 1). We have already shown that $F_{\mathrm{v}} / F_{\mathrm{m}}$ and $\sigma_{\mathrm{PSII}}(478)$ can be modified in a manner similar to that in Fig. 2A when Chaetoceros muelleri was grown under 2 PFDs (Fig. 1); therefore, some of this co-variability may arguably be the result of photoacclimation. However, the over-riding trend across the range of values for both $F_{\mathrm{v}} / F_{\mathrm{m}}$ and $\sigma_{\mathrm{PSII}}(478)$ from the cultures is clearly driven by taxonomic clusters of data (Fig. 2A). Few data sets are available to investigate whether this observation is also maintained within an algal class. However, our data for diatoms under nutrient-replete growth indicated a significant trend between $F_{\mathrm{v}} / F_{\mathrm{m}}$ and $\sigma_{\mathrm{PSII}}$ (478) (10 species, $\mathrm{r}^{2}=$ 0.426) for the substantial range of species tested (Fig. 3A). Recent studies have also demonstrated that some degree of co-variability between $F_{\mathrm{v}} / F_{\mathrm{m}}$ and $\sigma_{\mathrm{PSII}}$ (478) extends to the intra-clonal level of a single eukaryotic species (e.g. Emilinia huxleyi and Symbiodinium sp.; Suggett et al. 2007, 2008). However, the degree of variability is considerably smaller than that observed between species within an algal class (Fig. 3A), which is, in turn, small when compared to differences between eukaryotic groups (Fig. 2).

For the data examined here, the algae appear to group along 2 distinct 'trajectories'. The slope (or 'trajectory') of the $F_{\mathrm{v}} / F_{\mathrm{m}}$ versus $\sigma_{\mathrm{PSII}}$ (478) relationship is much steeper for cyanobacteria than it is for eukaryotes (Fig. 2A). The eukaryotic algae cluster (from high$F_{\mathrm{v}} / F_{\mathrm{m}}$, low $-\sigma_{\mathrm{PSII}}(478)$ to low $-F_{\mathrm{v}} / F_{\mathrm{m}}$, high- $\left.\sigma_{\mathrm{PSII}}(478)\right)$ in the following general order: diatoms, chlorophytes and crytophytes, prymnesiophytes and dinoflagellates, nanoflagellates (pelagophytes and prasinophytes) along a common trajectory. For the taxa measured, this ordering broadly corresponds to a decreasing trend in cell size. A similar relationship with cell size also appears within the diatom class (Fig. 3B).

The notable exceptions are for the prokaryotic prochlorophytes and the eukaryote rhodophyte Porphyridium cruentum, for which phenotypic co-variability 

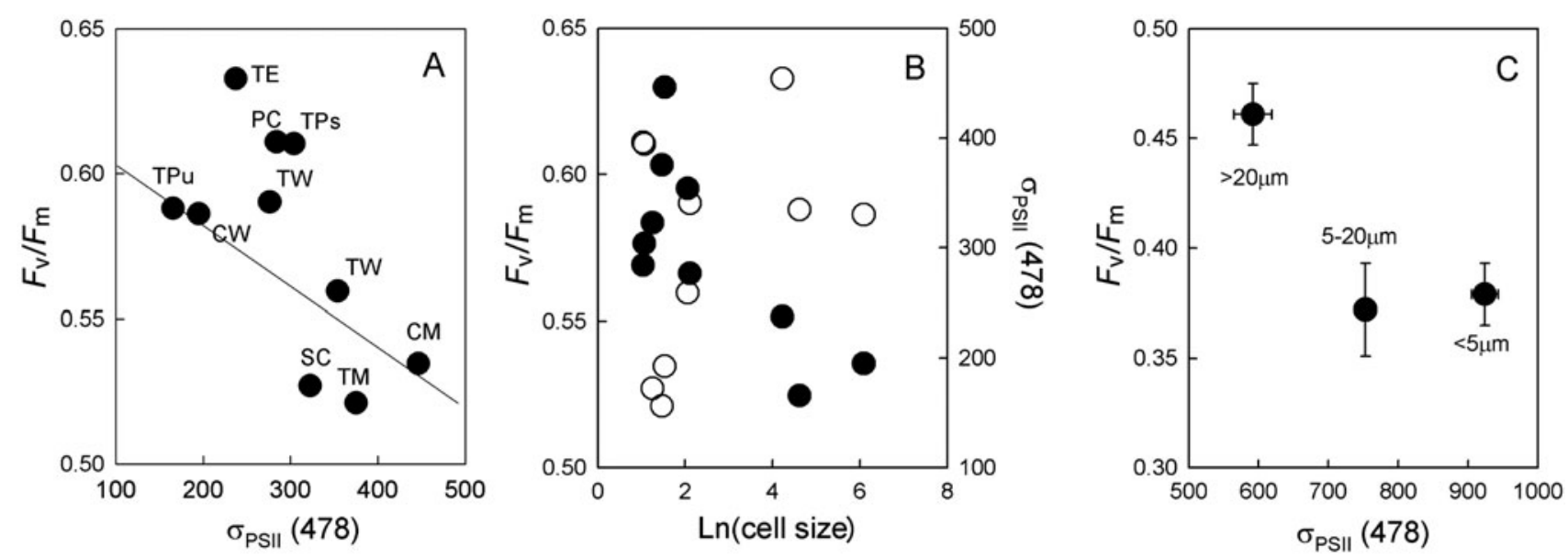

Fig. 3. Comparison of: (A) maximum PSII photochemical efficiency ( $F_{\mathrm{v}} / F_{\mathrm{m}}$, dimensionless) versus effective absorption cross section $\left(\sigma_{\mathrm{PSII}}(478), \AA^{2}\right.$ quanta $\left.^{-1}\right)$ for all diatom species: CM (Chaetoceros muelleri), CW (Coscinodiscus wallensi), SC (Skeletonema costatum), PC (Phaeodactylum cornutum), TE (Thalassiosira eccentrica), TM (Thalassiosira minima), TPs (Thalassiosira pseudonana), TPu (Thalassiosira puncitgera), TW (Thalassiosira weissflogii) (see Table 1). Note that each data point represents the mean value for all growth environments (where multiple data sets were available) to attempt to remove potential additional influences of growth light environment upon the relationship. Regression is $F_{\mathrm{v}} / F_{\mathrm{m}}=-0.0003 \times \sigma_{\mathrm{PSII}}(478)+0.665\left(\mathrm{r}^{2}=0.426, \mathrm{n}=10\right)$. The solid line indicates the chlorophyll-xanthophyll LHC 'trajectory' determined for regressions applied to laboratory culture data from Fig. 2. (B) Comparison of $F_{\mathrm{v}} / F_{\mathrm{m}}(\mathrm{O})$ and $\sigma_{\mathrm{PSII}}(478)(\mathbf{0})$ versus $\ln ($ cell size, $\mu \mathrm{m})$. Only the relationship between $\sigma_{\mathrm{PSII}}(478)$ and cell size was significant: $\sigma_{\mathrm{PSII}}(478)=-0.360 \times \ln ($ cell size $)+319\left(\mathrm{r}^{2}=0.372, \mathrm{n}=10\right)$. (C) $F_{\mathrm{v}} / F_{\mathrm{m}}$ versus $\sigma_{\mathrm{PSII}}(478)$ measured for 3 size classes isolated form natural phytoplankton communities from the Ría de Vigo, Spain (Cermeño et al. 2005) (Table 2). Data represent the means $( \pm \mathrm{SE})$ of all size-fractionation samples throughout the experimental period. Additional data to those already published were supplied by Patricia Estevez-Blanco and Pedro Cermeño

in $F_{\mathrm{v}} / F_{\mathrm{m}}$ and $\sigma_{\mathrm{PSII}}$ followed a trajectory similar to that for the eukaryotes and cyanobacteria, respectively. Rhodophytes and cyanobacteria are related by the characteristic that both employ phycobilisomes as lightharvesting antennae for PSII. Relatively low values of both $F_{\mathrm{v}} / F_{\mathrm{m}}$ and $\sigma_{\mathrm{PSII}}(478)$ have been documented previously for cyanobacteria, particularly those containing substantial concentrations of phycocyanin (Campbell et al. 1998, Raateoja et al. 2004). The fluorescence emission band from phycocyanin overlaps with that of chlorophyll a from PSII and, hence, can 'contaminate' the minimum fluorescence yield and so lead to lower values of $F_{\mathrm{v}} / F_{\mathrm{m}}$ (Campbell et al. 1998). This same feature likely explains the presence of the rhodophyte $P$. cruentum sp. within the 'cyanobacteria' rather than the 'eukaryotic' trajectory. However, some cyanobacteria with relatively low concentrations of phycocyanin within their phycobilipigment complement, e.g. Synechococcus sp. WH7803, still have relatively low values of both $F_{\mathrm{v}} / F_{\mathrm{m}}$ and $\sigma_{\mathrm{PSII}}(478)$. A substantial proportion of chlorophyll a within cyanobacteria is associated with PSI; therefore, it is possible that additional 'contamination' of the minimum yield $\left(F_{0}\right)$ may originate from PSI chlorophyll a fluorescence (Campbell et al. 1998).

Low values of $\sigma_{\text {PSII }}$ (478) for cyanobacteria almost certainly result from the blue excitation waveband employed by the Fast ${ }^{\text {tracka }}$ FRR fluorometer, which is an inefficient excitation source for these organisms since
PSII absorption is dominated by phycobilisomes (Raateoja et al. 2004, Suggett et al. 2004, Johnsen \& Sakshaug 2007). Fluorescence excitation spectra demonstrate that the PSII action spectrum for cyanobacteria is typically much lower in blue than in orange light (Fig. 2B); for example, Synechococcus sp. WH7803 exhibits a value of $\sigma_{\text {PSII }}(478)$ that is only $20 \%$ of that when excited at $550 \mathrm{~nm}$, i.e. $\sigma_{\mathrm{PSII}}(550)$ will be a factor of 5 greater than $\sigma_{\text {PSII }}(478)$. For the blue excitation wavelengths currently employed by the FRR, a clear difference in trajectory is thus evident between phytoplankton with a phycobilisome- (cyanobacteria and rhodophytes) versus a chlorophyll-xanthophyll- (chl $a / b$, chl $a / c$ or chl a/peridinin) based light-harvesting complex (LHC) (Fig. 2). Consideration of the excitation wavelength is thus crucial when interpreting in situ data. For example, rigorous interpretation of observed gradients in values of $\sigma_{\text {PSII }}(478)$ in an ecological context strictly requires normalization to the in situ irradiance spectrum, i.e. $\sigma_{\text {PSII }}$ (in situ) (Moore et al. 2006b, Suggett et al. 2006b). However, we note that $\sigma_{\mathrm{PSII}}(478)$ is likely to correlate well with $\sigma_{\text {PSII }}$ (in situ) for many natural waters, due to the dominance of blue wavebands, particularly where dominance of light absorption is by chlorophyll-xanthophyll LHCs.

Additional consideration of the expected relationship between $F_{\mathrm{v}} / F_{\mathrm{m}}$ and $\sigma_{\mathrm{PSII}}$ for the prochlorophytes is more problematic. Few FRR data currently exist for 
prochlorophytes under controlled growth conditions. Published data by Steglich et al. (2001) and Bruyant et al. (2005) both demonstrate that Prochlorococcus marinus is characterized by relatively high values of $F_{\mathrm{v}} / F_{\mathrm{m}}$ (ca. 0.55 to 0.65 ) and low values of $\sigma_{\text {PSII }}$ (478) (ca. 300 to 600), suggesting that they fall along the eukaryote rather than the cyanobacteria trajectory (Fig. 2). Such a suggestion would seem logical since prochlorophyte pigments are dominated by divinyl chlorophylls with only relatively low concentrations of phycoerythrin (Penno et al. 2000). Furthermore, Prochlorococcus sp. appear to have values for RCI:RCII that are lower than for Synechococcus sp. by a factor of 3 (Partensky et al. 1997), and so are more similar to eukaryotes in this regard (see Suggett et al. 2007). Consequently, prochlorophytes likely maintain a relatively high PSII absorption cross section and potentially exhibit little 'contamination' of PSII fluorescence by phycobilipigment or PSI fluorescence that would act to lower $F_{\mathrm{v}} / F_{\mathrm{m}}$. However, given the apparent wide diversity of the prochlorophytes, we cannot consider this limited data set to be indicative of the physiology of the group as a whole.

Understanding the mechanisms that drive the covariability between $F_{\mathrm{v}} / F_{\mathrm{m}}$ and $\sigma_{\mathrm{PSII}}$ observed across eukaryotic algal classes requires us to examine the underlying nature of the functional absorption cross section. Several studies have previously demonstrated that variability of $\sigma_{\mathrm{PSII}}$ can be accounted for by the corresponding changes to the concentration, type and arrangement of pigmentation within the thylakoid membranes in addition to the associated RCII concentration (Suggett et al. 2004, Moore et al. 2006b). Conse-
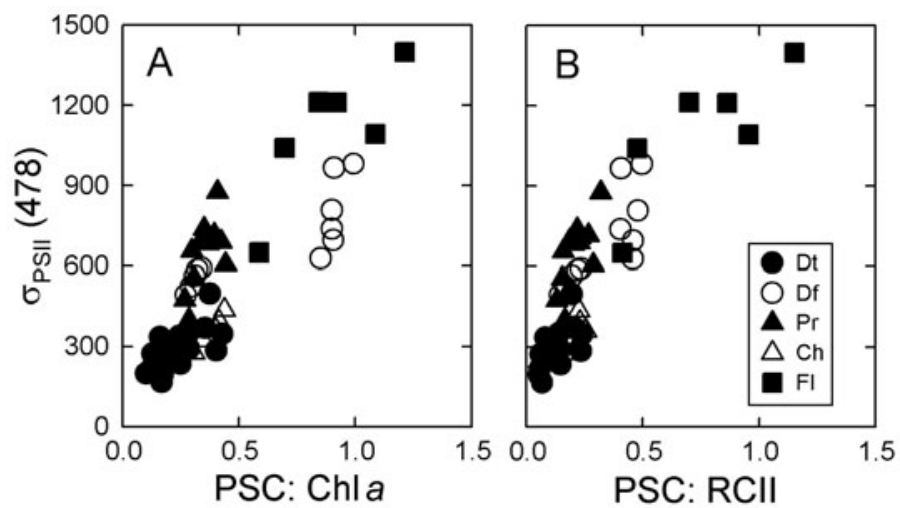

Fig. 4. Relationship between FRR measures of the effective absorption cross section $\left(\sigma_{\text {PSII }}(478), \AA^{2}\right.$ quanta $\left.^{-1}\right)$ and the ratio of: (A) photosynthetic carotenoids (PSC) to chlorophyll a (chl a) concentration $\left(\mathrm{g} \mathrm{g}^{-1}\right.$ ) and (B) PSC to PSII reaction centre (RCII) concentration $\left(\mathrm{g} \mu \mathrm{mol}^{-1}\right.$ ). Data are included only for species of diatoms (Dt), dinoflagellates (Df), prymnesiophytes $(\mathrm{Pr})$, chlorophytes $(\mathrm{Ch})$ and the flagellated pelagophytes and prasinophytes $(\mathrm{Fl})$ from Fig. 2, since species in all other groups lack PSC quently, a tight relationship exists between measurements of $\sigma_{\text {PSII }}(478)$ and the ratio of photosynthetic carotenoid (PSC) to RCII concentration for those taxa whose absorption at $478 \mathrm{~nm}$ is dominated by these carotenoids (Fig. 4).

The clear inverse correlation between $F_{\mathrm{v}} / F_{\mathrm{m}}$ and $\sigma_{\mathrm{PSII}}$ (478), which additionally appears to correlate with cell size for eukaryotes, may be driven by a number of factors related to the energetics of light absorption and excitation energy transfer to reaction centres. These factors have likely acted as selective pressures during phytoplankton evolution. Overall an inverse relationship between the photochemical efficiency of PSII $\left(F_{\mathrm{v}} / F_{\mathrm{m}}\right)$ and the amount of pigment within the antenna serving the reaction centre (which will largely dictate $\left.\sigma_{\mathrm{PSII}}\right)$ is expected in energetic terms. Increased numbers of pigment molecules within an antenna will increase the lifetime of an exciton within the antenna and, hence, the probability of thermal dissipation (Lavergne \& Joliot 2000). As such, photochemical efficiencies are predicted to decrease with increasing antenna size (Lavergne \& Joliot 2000), as was observed (Fig. 2).

Many physiological traits have a strong dependence on cell size (Geider et al. 1986, Finkel 2001, Irwin et al. 2006), which consequently appears to have experienced strong evolutionary selection pressure (Finkel et al. 2007). Such evolutionary pressure on cell size has presumably also driven a diversification of lightharvesting strategies, resulting in the association of higher $\sigma_{\mathrm{PSII}}$ (and, hence, lower $F_{\mathrm{v}} / F_{\mathrm{m}}$ ) with smaller cells (Figs. 2A \& 3). Phytoplankton frequently inhabit nutrient-limited environments (e.g. Cullen et al. 1992, Kolber et al. 1994, Graziano et al. 1996, Moore et al. 2006a, Behrenfeld et al. 2006); consequently, selection pressures for these photoautotrophs would be broadly expected to maximise light harvesting according to a given amount of biomass (carbon) or resource availability (nutrient). A number of hypotheses can be formulated from these basic premises.

Firstly, physical constraints associated with pigment and RCII packaging are well known to alter the lightharvesting capacity of eukaryotic algae (Duyens 1956, Morel \& Bricaud 1981, Falkowski \& Raven 2007). As pigment concentrations increase within a cell, self shading within the thylakoid membranes effectively reduces the efficiency of light capture by individual pigment molecules; this is known as the package effect (Morel \& Bricaud 1981, Berner et al. 1989). Given a constant cellular pigment concentration, the absorption per unit pigment is predicted to decrease as cell size increases due to the susceptibility of larger cells to the package effect (Morel \& Bricaud 1981). Consequently a decreased $\sigma_{\text {PSII }}$ might be expected to result from a higher package effect within large cells (Fig. 3; 
Moore et al. 2005). However, packaging cannot explain all of the noted trends. In particular the strong correlation of higher $\sigma_{\text {PSII }}(478)$ with PSC:chl $a$ and PSC:RCII (Fig. 4) along with decreased $F_{\mathrm{v}} / F_{\mathrm{m}}$ (Fig. 2A) suggest that the antenna size also varies between groups and, in particular, is larger for the smaller taxa.

A second consideration is the area of photosynthetic membrane space available per unit cell volume, which will decrease as cell size decreases (Raven 1986, 1999). Photosynthetic membranes contain light-harvesting complexes and reaction centre complexes, both of which contain pigmented and non-pigmented complexes, including the cytochrome b6/f complex and the chloroplast ATP synthase. Assuming that the membrane is densely packed (Kirchhoff 2008), competition for space between non-pigmented and pigmented complexes will result in the light absorbed per unit membrane surface being higher when the ratios of light-harvesting complexes relative to reaction centre and non-pigmented complexes are higher (Lavergne \& Joliot 2000). Larger antenna sizes will thus increase the light absorbed per unit membrane surface (Lavergne \& Joliot 2000) and, consequently, may offset the decreased membrane space per unit cell volume that accompanies smaller cell size (Raven 1986, 1999). Small eukaryotes may therefore have evolved higher $\sigma_{\text {PSII }}$ (i.e. larger LHCs or a higher LHC:RCII ratio) in order to maintain biomass-specific light-harvesting rates.

Thirdly, the cellular resources required for the production of reaction centres are greater than those required for pigment-protein antenna complexes (this is particularly the case for iron). Consequently, selective pressure for larger $\sigma_{\mathrm{PSII}}$ (and $\sigma_{\mathrm{PSI}}$ ) has been hypothesised to occur in resource-limited environments (Bibby et al. 2001, Strzepek \& Harrison 2004, Moore et al. 2006b), which will also favour small cells (Irwin et al. 2006).

Finally, for prokaryotes, large membrane intrinsic antennae have been hypothesised to be a limiting factor in PSII repair, again imposing selective pressure on $\sigma_{\text {PSII }}$ (Six et al. 2008). In the case of eukaryotes a small cellular pool of RCIIs and a higher LHC:PSII ratio (and thus larger $\sigma_{\text {PSII }}$ ) may be adequate in the stable light regimes frequently dominated by small cells. In contrast, the resource-rich but highly variable light environments, typically inhabited by larger diatoms, for example (Falkowski \& Oliver, 2007), may favour a smaller antenna (i.e. lower $\sigma_{\text {PSII }}$ ), which can be readily disassembled to enable rapid replacement of the core D1 protein of PSII. Consideration of membrane diffusion rates is likely required in this context (Kirchhoff 2008). Overall each of the hypotheses proposed to explain higher $\sigma_{\mathrm{PSII}}$ at smaller cell sizes warrant further investigation in future studies.

\section{Mixed community signals of $F_{\mathrm{v}} / F_{\mathrm{m}}$ versus $\sigma_{\mathrm{PSII}}$}

Many common features have been observed in FRR fluorescence data from field studies. In particular, values of $F_{\mathrm{v}} / F_{\mathrm{m}}$ are highest and $\sigma_{\mathrm{PSII}}$ (478) are lowest for coastal well-mixed waters dominated by large fastgrowing diatom cells. Values of $F_{\mathrm{v}} / F_{\mathrm{m}}$ decrease and values of $\sigma_{\text {PSII }}$ (478) increase with enhanced water column stability and dominance by small flagellated eukaryotes (Aiken et al. 2004, Moore et al. 2005, 2006b, Fishwick et al. 2006). This same trend is observed when different size fractions of mixed community samples are individually measured (Cermeño et al. 2005; Fig. 3C), specifically, that cells within the largest size fraction exhibit the highest values of $F_{\mathrm{v}} / F_{\mathrm{m}}$ and the lowest values of $\sigma_{\text {PSII }}(478)$. The cell size or algal group within the mixed community that contributes the greatest proportion of the total chlorophyll a fluorescence appears to dominate the mixed community value measured for $F_{\mathrm{v}} / F_{\mathrm{m}}$ and $\sigma_{\mathrm{PSII}}$ (478) (Suggett et al. 2004).

Field data demonstrate that the inverse relationship between $F_{\mathrm{v}} / F_{\mathrm{m}}$ and $\sigma_{\mathrm{PSII}}$ (478) observed for laboratorygrown monocultures is conserved for mixed phytoplankton communities examined across relatively large spatial scales (Fig. 5). However, the trajectories are highly variable between data sets (Fig. 5). Considering the laboratory FRR fluorometry, the variability in trajectories could be interpreted as different mixtures of Synechococcus sp. and eukaryotic populations within the community's chlorophyll a fluorescence yield. In the case of the polar studies (Mertz-Polynya; Vaillancourt et al. 2003; CROZEX; Moore et al. 2007), Synechococcus sp. were rare along these sampling transects and, consequently, the 2 data sets overlap along the same trajectory. Unfortunately, it is impossible to rule out the possibility of instrument and sampling artefacts when comparing these various data sets, specifically, calibration of $\sigma_{\text {PSII }}(478)$ and not accounting for background fluorescence (the effect of the blank; Cullen \& Davis 2003). Generating absolute values of $\sigma_{\text {PSII }}(478)$ requires accurate calibration of the intensity of the LEDs used to induce the fluorescence yields. Whilst such calibrations are performed at the time of instrument service, it is impossible to gauge the amount of subsequent drift without regular internal standardisation by the operator. Accurate values of $\sigma_{\text {PSII }}$ (478) are also dependent upon whether instrument bias has been accounted for at the time of fitting the KPF model to the fluorescence transients (Laney \& Letelier 2008). Further, the consideration of an additional sample blank is important for maximizing the accuracy of values of $F_{\mathrm{v}} / F_{\mathrm{m}}$, but not $\sigma_{\mathrm{PSII}}$ (Cullen \& Davis 2003, Laney \& Letelier 2008). Background fluorescence will lead to significant reductions to $F_{\mathrm{v}} / F_{\mathrm{m}}$ for chlorophyll a concentrations less than ca. 

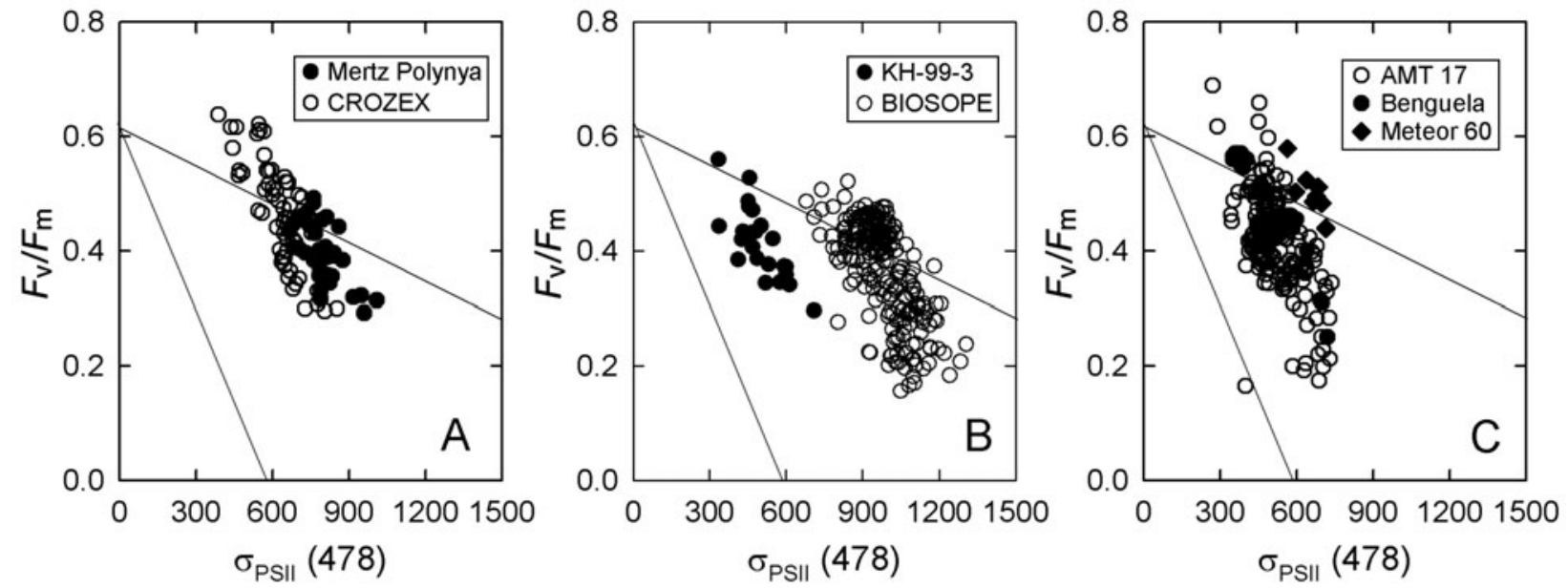

Fig. 5. Values of maximum PSII photochemical efficiency $\left(F_{\mathrm{v}} / F_{\mathrm{m}}\right.$, dimensionless), and effective absorption cross section $\left(\sigma_{\mathrm{PSII}}\right.$ (478), $\AA^{2}$ quanta $^{-1}$ ), measured by FRR fluorometry from: (A) Mertz-Polynya (Vaillancourt et al. 2003) and CROZEX (Moore et al. 2007) polar waters, (B) KH-99-3 (Suzuki et al. 2002) and BIOSOPE (Prášil unpubl. data) and (C) AMT 17 and Meteor 60 (Moore unpubl. data) and Benguela upwelling (Fishwick et al. 2006) and in the Atlantic. Details of the original sources of these data sets are given in Table 2. Phycobilisome and chlorophyll-xanthophyll LHC 'trajectories' determined for regressions applied to laboratory culture data from Fig. 2 are overlaid

1 to $10 \mathrm{mg} \mathrm{m}^{-3}$ (Suggett et al. 2006a), i.e. concentrations observed across the majority of transoceanic transects for the FRR data in Fig. 5. To eliminate such uncertainty, we next focus on data collected with the same inter-calibrated instruments and protocols (see Moore et al. 2005, 2006a).

Sampling campaigns that cover substantial changes in phytoplankton community structure typically display large differences in FRR fluorescence signatures (Fig. 6). Cruises JR98 and FISHES encountered phytoplankton communi-

Fig. 6. Values of maximum PSII photochemical efficiency $\left(F_{\mathrm{v}} / F_{\mathrm{m}}\right.$, dimensionless) and effective absorption cross section ( $\sigma_{\text {PSII }}(478), \AA^{2}$ quanta $^{-1}$ ) measured by FRR fluorometry during: (A) FISHES (Moore et al. 2005) and JR98 (Moore et al. 2006b) and (B) during AMT 15 (Hickman unpubl. data). Phycobilisome and chlorophyll-xanthophyll LHC 'trajectories' determined for regressions applied to laboratory culture data from Fig. 2 are indicated. Colours indicate the relative proportion of the cyanobacterial diagnostic pigment (DP) zeaxanthin (g zea:g $\Sigma D^{-1}$ ). $\Sigma D P$ refers to the sum of fucoxanthin, peridinin, alloxanthin, 19'-butanoyloxyfucoxanthin (but), 19'-hexanoyloxyfucoxanthin (hex), chlorophyll $b$ and zeaxanthin (see 'Results and discussion: Mixed community...'). (C, D) Values of $\sigma_{\text {PSII }}(478)$ compared against the ratio of PSC to chl a concentration $\left(\mathrm{g} \mathrm{g}^{-1}\right)$ for: (C) FISHES and JR98 and (D) AMT 15. Colours indicate the relative proportion of the prochlorophyte DP $\mathrm{chl} b$ (g chl $\left.b: g \mathrm{DP}^{-1}\right)$. (E, F) Values of $\sigma_{\text {PSII }}$ compared against the proportion of total community DP contributed by both $19^{\prime}$-hex and 19'-but (i.e. Hex $/ \Sigma \mathrm{DP}+\mathrm{But} / \Sigma \mathrm{DP}$ ) for: (E) FISHES and JR98 and (F) AMT 15
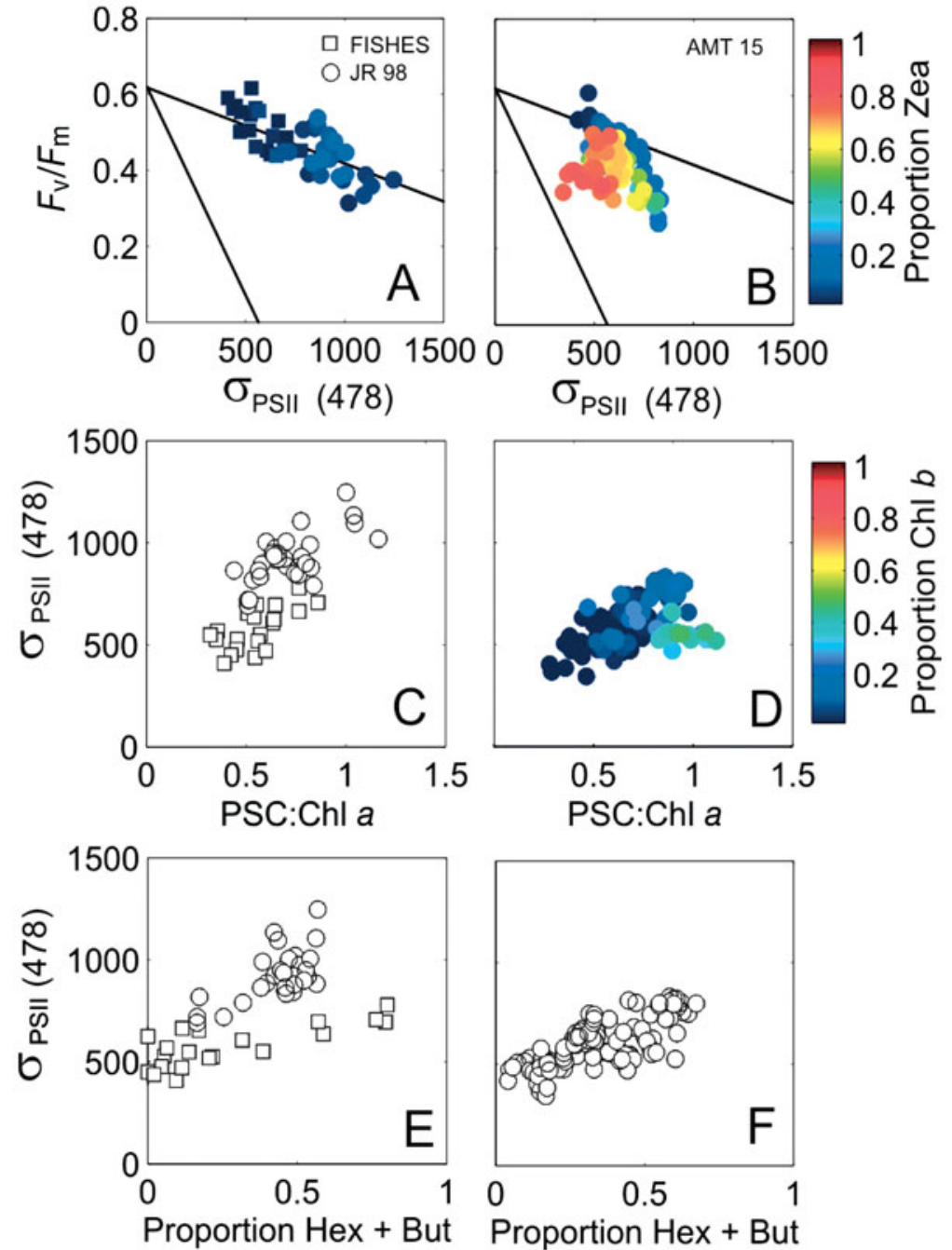
ties that shifted from dominance by diatoms to nanoflagellates (Moore et al. 2006b) and by large diatoms to small diatoms and flagellates (Moore et al. 2005), respectively. Trends of $F_{\mathrm{v}} / F_{\mathrm{m}}$ and $\sigma_{\mathrm{PSII}}$ (478) collapse clearly along a single trajectory (Fig. 6A). Although Synechococcus sp. was encountered during JR98, the diagnostic marker pigment for cyanobacteria, zeaxanthin, remained relatively low throughout that cruise. Synechococcus sp. therefore remained a minor component of the phytoplankton community and did not significantly affect the physiological indices. As demonstrated for the laboratory-grown monocultures, the values of $\sigma_{\text {PSII }}$ (478) closely correspond with the PSC to chlorophyll a ratio (Fig. 6C).

In contrast to the study regions for JR98 and FISHES, basin-scale open-ocean cruises encounter varying proportions of prochlorophytes, Synechococcus sp. and picoeukaryotes and yield more complex relationships between $F_{\mathrm{v}} / F_{\mathrm{m}}$ and $\sigma_{\mathrm{PSII}}(478)$ (Figs. $5 \& 6$ ). For example, for the AMT 15 data (Fig. 6B), populations with low cyanobacterial dominance (i.e. low zeaxanthin: chlorophyll ratios) display a similar inverse correlation between $\sigma_{\mathrm{PSII}}(478)$ and $F_{\mathrm{v}} / F_{\mathrm{m}}$ as that found in eukaryotic laboratory cultures (Fig. 2). However, regions with relatively high zeaxanthin concentrations and, hence, increased dominance of the community biomass by Synechococcus sp. were associated with a cluster of low- $\sigma_{\mathrm{PSII}}(478)$, low $-F_{\mathrm{v}} / F_{\mathrm{m}}$ values (Fig. 6B). It follows that the AMT 15 data are consistent with a mixture of the 2 trajectories as would be expected given the community structure. Considerable co-variability was also observed between $\sigma_{\mathrm{PSII}}(478)$ and the PSC:chl a ratio in the AMT 15 data (Fig. 6C). Regions with significant relative increases of chlorophyll $b$, a diagnostic marker pigment indicating prochlorophytes and/or chlorophytes, exhibited relatively low $\sigma_{\text {PSII }}$ (478) (Fig. 6D); this is also generally consistent with the low values of $\sigma_{\text {PSII }}$ observed for these phytoplankton taxa in culture experiments (Fig. 2).

Analysis of data from the Benguela upwelling off the south-west coast of South Africa has also demonstrated that cross-shelf trends of $F_{\mathrm{v}} / F_{\mathrm{m}}$ and $\sigma_{\mathrm{PSII}}(478)$ can be broadly correlated with community structure (Fishwick et al. 2006). Once again, values of $F_{\mathrm{v}} / F_{\mathrm{m}}$ increased and $\sigma_{\text {PSII }}$ (478) decreased as the community changed from diatoms to flagellated (pico-) eukaryotes. Diagnostic pigments (DP) for diatoms (fucoxanthin), dinoflagellates (peridinin), picoeukaryotes (alloxanthin, 19'-butanoyloxyfucoxanthin, 19'-hexanoyloxyfucoxanthin, chlorophyll $b$ ) and prokaryotes (zeaxanthin) were used to partition the phytoplankton community into the percentage contributions of various taxonomic groups (Fishwick et al. 2006). This approach demonstrated that $87 \%$ of the variance in $\sigma_{\text {PSII }}(478)$ and $71 \%$ of the variance in $F_{\mathrm{v}} / F_{\mathrm{m}}$ could be explained by variabil- ity in the percent of picoeukaryotes. In contrast, only $32 \%$ of the variance in $\sigma_{\mathrm{PSII}}$ and $27 \%$ of the variance in $F_{\mathrm{v}} / F_{\mathrm{m}}$ could be explained by variability in the percent diatoms. The cause of correlation coefficients observed between FRR variables and the \%DP that were lower for diatoms than for picoeukaryotes is not clear, but may reflect limitations inherent to DP-type reconstructions. For example, in the current context, certain groupings used by Fishwick et al. (2006) will contain organisms with very different PSII antenna structures. For example, the picoeukaryote grouping will contain both pelagophytes (19'-butanoyloxyfucoxanthin) and chlorophytes (chl $b$ ), which have high and low values of $\sigma_{\text {PSII }}$ (478), respectively (Fig. 2).

Consequently, we can repeat the approach used by Fishwick et al. but considering instead a more detailed DP classification to account for each of the (pico)-eukaryotic groups. Thus, we assume that 19 '-butanoyloxyfucoxanthin/ $\Sigma$ (fucoxanthin, peridinin, alloxanthin, 19'-butanoyloxyfucoxanthin, 19'-hexanoyloxyfucoxanthin, chlorophyll $b$ and zeaxanthin) (hereafter But/ $\Sigma \mathrm{DP}$ ) provides some measure of relative dominance by pelagophytes; similarly, Hex/ $/ \mathrm{DP}$ is the proportion of prymnesiophytes; Fuco/ $\Sigma \mathrm{DP}$, diatoms; etc. For the JR98 and FISHES data sets that were dominated by eukaryotes, high positive co-variability was observed between $\sigma_{\text {PSII }}$ (478) (Fig. 6E) or $F_{\mathrm{v}} / F_{\mathrm{m}}$ (not

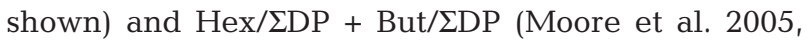
$2006 b)$. This is fully consistent with the laboratory data that indicated that pelagophytes and prymnesiophytes have a high $\sigma_{\text {PSII }}$ (478) relative to other eukaryotes (Fig. 2). Similarly, despite the complicated community structure encountered during AMT 15 (Fig. 6D), >50\% of the variance in $\sigma_{\text {PSII }}(478)$ across the Atlantic Ocean from $\sim 50^{\circ} \mathrm{N}$ to $40^{\circ} \mathrm{S}$ could be explained by Hex/ $/ \mathrm{DP}+$

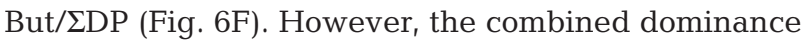
of these groups was a poor predictor of $F_{\mathrm{v}} / F_{\mathrm{m}}\left(\mathrm{r}^{2}<0.1\right.$, $\mathrm{n}=118$ ) in this case, due to the influence of the Synechococcus sp. populations in parts of the transect (Fig. 6B). In other words, a more sophisticated multivariate approach is required to account for natural communities composed of mixtures of different populations with a range of PSII characteristics. Finally, stepwise linear regression for each of the DP/ $/ \mathrm{DP}$ against FRR measures of $F_{\mathrm{v}} / F_{\mathrm{m}}$ or $\sigma_{\text {PSII }}$ (478) for the AMT 15 transect results in the following relationships:

$F_{\mathrm{v}} / F_{\mathrm{m}}=$

$0.395 \times \mathrm{But} / \Sigma \mathrm{DP}-0.492 \times \mathrm{Hex} / \Sigma \mathrm{DP}-0.095 \times \mathrm{Zea} / \Sigma \mathrm{DP}$

$\sigma_{\text {PSII }}(478)=$

$941 \times \mathrm{Hex} / \Sigma \mathrm{DP}-128 \times \mathrm{Chl} b / \Sigma \mathrm{DP}+92.1-\mathrm{Fuco} / \Sigma \mathrm{DP}$

where these are linear combinations and can explain the majority of the variability in $F_{\mathrm{v}} / F_{\mathrm{m}}\left(\mathrm{r}^{2}=0.61, \mathrm{n}=118, \mathrm{p}<\right.$ $0.001)$ and $\sigma_{\text {PSII }}\left(\mathrm{r}^{2}=0.71, \mathrm{n}=118, \mathrm{p}<0.001\right)$. Data sets collected throughout the Atlantic Ocean thus demon- 
strate the inherent relationship between phytoplankton community structure and the fundamental characteristics of PSII as measured using FRR fluorescence.

\section{Physiological signatures of nutrient limitation}

Selective pressure from prevailing environmental conditions between water bodies simultaneously drives both the taxonomic composition of the phytoplankton community and the physiological status of the resident taxa. It is well established that well-stratified, low-nutrient oceanic waters become dominated by small-celled communities composed of Prochlorococcus sp., Synechococcus sp. and picoeukaryotes (e.g. Irwin et al. 2006). As described in the preceding section, changes in the taxonomic composition of the community (e.g. as inferred from diagnostic pigments) will impart a taxonomic signature on $F_{\mathrm{v}} / F_{\mathrm{m}}$ and $\sigma_{\mathrm{PSII}}(478)$. However, $F_{\mathrm{v}} / F_{\mathrm{m}}$ and $\sigma_{\mathrm{PSII}}$ may also be modified in response to physiological stress (Kolber et al. 1988, Herzig \& Falkowski 1989, Geider et al. 1993b). Significantly, within a taxon, $F_{\mathrm{v}} / F_{\mathrm{m}}$ decreases and $\sigma_{\mathrm{PSII}}(478)$ increases in response to nutrient starvation and other environmental stresses, e.g. photoinhibition and/or UV radiation (Vassiliev et al. 1994, Ragni et al. 2008). This pattern of change essentially reflects that observed in the taxonomic shift from diatoms to picoplankton (compare Fig. 1 with Fig. 2A).

Growth rates appear to be lower than would be predicted for picoplankton-dominated, low-nutrient oceanic waters. Such low growth rates would suggest nutrient limitation (e.g. Marañon 2005), despite the documented potential for balanced growth in these regions (e.g. Goldman et al. 1979, Falkowski et al. 1992). As discussed above, the low values of $F_{\mathrm{v}} / F_{\mathrm{m}}$ and high values of $\sigma_{\text {PSII }}(478)$ frequently observed in these regions cannot only be attributed to environmental stress (e.g. nutrient starvation). Furthermore, values of $F_{\mathrm{v}} / F_{\mathrm{m}}$ can be maintained at the maximal values for a given taxon under nutrient-limited balanced growth (Parkhill et al. 2001). These considerations confound unambiguous interpretation of $F_{\mathrm{v}} / F_{\mathrm{m}}$ and $\sigma_{\mathrm{PSII}}(478)$ for natural populations, primarily because the observed magnitudes likely represent a composite of both the phytoplankton taxonomy and nutritional status, but secondarily because taxonomic shifts and stress could both result from environmental change. Consequently, FRR measurements will be indicative of both long- and short-term environmental control upon marine primary productivity. Therefore, a key question to ask is just how much of the variability of FRR fluorescence signatures is driven by nutrient availability acting in a physiological (stress) sense? We address this question in the following section.

\section{Nutrient limitation of natural communities}

One of the fundamental applications of FRR fluorometry has been to examine the nutrient status of phytoplankton communities (Kolber et al. 1994, Behrenfeld et al. 1996, 2006, Olson et al. 2000, Boyd \& Abraham 2001, Sosik \& Olson 2002, Moore et al. 2006a, 2008). The majority of these studies have focused on low-Fe, high-nutrient, low-chlorophyll a (HNLC) ocean regions. Oceanic transects have demonstrated the effect of HNLC conditions on phytoplankton physiology. For example, FRR fluorescence measured on transects by Sosik \& Olson (2002) demonstrated that decreases in $F_{\mathrm{v}} / F_{\mathrm{m}}$ coincided with an increase in cell size, as the community changed from cyanobacteria- to diatomdominated, and as waters became more Fe-depleted (Fig. 7). From the laboratory data, we would expect the larger diatoms to exhibit higher values of $F_{\mathrm{v}} / F_{\mathrm{m}}$ if growth were nutrient replete. However, the most direct evidence of the effect of nutrient availability upon FRR fluorescence signatures has come from experimental nutrient addition experiments upon natural populations.

IronEx I was the first experiment on an unenclosed natural community to demonstrate the effect of nutrient enrichment upon FRR-based measures of phytoplankton physiology; specifically, a rapid (24 to $48 \mathrm{~h}$ ) and substantial (70 to $100 \%$ ) increase of $F_{\mathrm{v}} / F_{\mathrm{m}}$ and simultaneous decrease (20 to $50 \%$ ) of $\sigma_{\text {PSII }}$ followed fertilisation of HNLC waters with iron (Kolber et al. 1994). Such a response reflects the relief from nutrient starvation, as discussed previously. Changes in $F_{\mathrm{v}} / F_{\mathrm{m}}$ during IronEx I were observed consistently across all size classes, indicating a general physiological response by all components of the community. Other in situ iron release experiments have similarly shown a clear physiological response within $24 \mathrm{~h}$ of the experiment initiation (Boyd \& Abraham 2001, Gervais et al. 2002). For example, Boyd \& Abraham's (2001) FRR fluorometry from the SOIREE iron release programme detected a $35 \%$ increase in $F_{\mathrm{v}} / F_{\mathrm{m}}$ within $24 \mathrm{~h}$ of Fe-addition, but a much larger response of both $F_{\mathrm{v}} / F_{\mathrm{m}}$ and $\sigma_{\mathrm{PSII}}(478)$ over the subsequent $6 \mathrm{~d}$. It should also be noted that community changes from picoeukaryote- to diatomdominated were simultaneously occurring over this period (Fig. 7). Similar changes on the order of 10 to $30 \%$ have been observed in a number of such ironrelease experiments.

Bottle experiments can also demonstrate the short timescale physiological response to nutrient addition. Such experiments can be conducted over relatively short periods (48 h) so as to largely preclude a change in the taxonomic composition of the community and therefore allow the physiological response to be assessed (Moore et al. 2008). For example, in the 

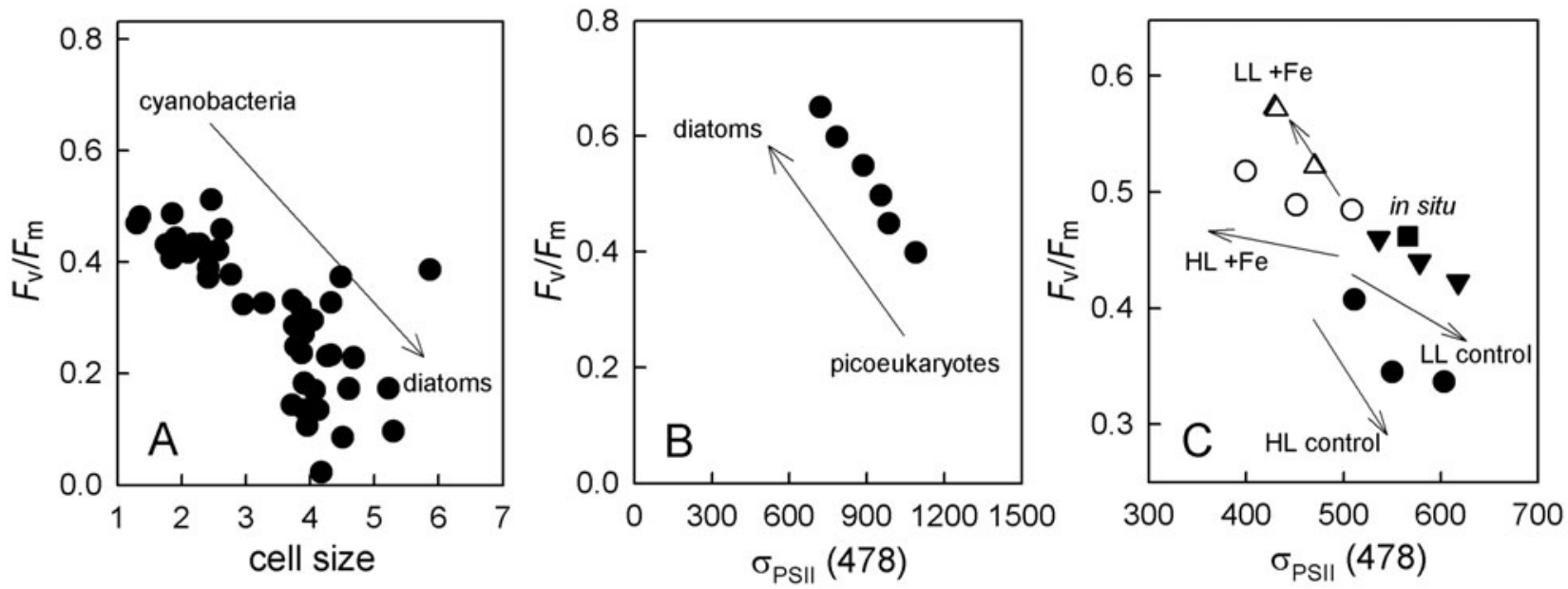

Fig. 7. (A) Relationship of maximum PSII photochemical efficiency ( $F_{\mathrm{v}} / F_{\mathrm{m}}$, dimensionless) measured by FRR fluorometry to mean cell diameter $(\mu \mathrm{m})$ from a transect across the Antarctic Polar Frontal Zone (Sosik \& Olson 2002) and (B) relationship of $F_{\mathrm{v}} / F_{\mathrm{m}}$ to $\sigma_{\text {PSII }}(478)\left(\AA^{2}\right.$ quanta $\left.^{-1}\right)$ within the Polar Front Antarctic Circumpolar Current during the SOIREE iron fertilisation experiment (Boyd \& Abraham 2001). Values of $\sigma_{\mathrm{PSII}}(478)$ are from all depths, but are plotted as the means from bins of $F_{\mathrm{v}} / F_{\mathrm{m}}$ separated by 0.05 units. (C) Relationship between FRR fluorescence measurements of $F_{\mathrm{v}} / F_{\mathrm{m}}$ and $\sigma_{\mathrm{PSII}}(478)$ from discrete bioassay incubations of surface water during CROZEX (Moore et al. 2007; our Table 2). Incubations were performed in the presence (+Fe, open symbols) and absence (control, filled symbols) of iron under low-light (LL, triangles) and high-light (HL, circles) photon flux densities. Also shown is the initial value (filled square). FRR measurements were made on Days 1, 3 and 5 of the incubation. Each data point is the mean of triplicate incubations for each treatment. Arrows indicate the increase in time of incubation and the corresponding direction of change for $F_{\mathrm{v}} / F_{\mathrm{m}}$ and $\sigma_{\mathrm{PSII}}$ for the 4 treatments (with respect to the corresponding in situ mean value recorded at the time of sample collection). Note the different axis scales between Panels B and C

case of combined light and Fe-manipulations during CROZEX (Moore et al. 2007; our Fig. 7C), the physiological response to increased Fe-supply was observed but modulated according to the simultaneous photoinhinbitory damage caused by increased irradiance. Smaller scale physiological changes have also been observed for bottle experiments conducted during the Atlantic Ocean spring bloom in response to iron addition (an increase of $F_{\mathrm{v}} / F_{\mathrm{m}}$ and decrease of $\sigma_{\mathrm{PSII}}(478)$ by 10 to $15 \%$; Moore et al. 2006a; see Fig. 8).

Behrenfeld et al. (1996) demonstrated a large alteration in the physiology of prokaryotic-dominated communities within $24 \mathrm{~h}$ of Fe-addition during IronEx II (Fig. 8). Specifically, $F_{\mathrm{v}} / F_{\mathrm{m}}$ and $\sigma_{\mathrm{PSII}}$ increased by a factor of 2 and 4, respectively (Fig. 8). Curiously, this physiological response is not what would be expected from preferential RCII re-activation/synthesis from laboratory observations, as noted previously. Also, this result does not appear to be consistent with other Feenrichment experiments. Recently Behrenfeld et al. (2006) interpreted these physiological changes as indicative of a re-coupling to PSII of detached ironstress-induced antenna proteins, resulting in a simultaneous increase of $\sigma_{\mathrm{PSII}}$ and lower values of $F_{\mathrm{o}}$ and $F_{\mathrm{m}}$ hence increasing $F_{\mathrm{v}} / F_{\mathrm{m}}$. Such a response may be specific to relieving Fe-limitation of prokaryotes.

Iron additions within HNLC regions provide key examples where FRR fluorescence indeed provides a (relative) indicator of physiological state. In contrast, relief of nutrient limitation in nutrient-addition experiments conducted in low-nitrate, low-chlorophyll a regions typically produces no detectable difference (Graziano et al. 1996, Behrenfeld et al. 2006, Moore et al. 2008), or a relatively small change in $F_{\mathrm{v}} / F_{\mathrm{m}}$ or $\sigma_{\mathrm{PSII}}$ (478) (Fig. 8). A number of bioassay experiments have now been performed upon Atlantic open ocean communities to examine co-limitation by multiple nutrients (N-P-Fe) (e.g. Moore et al. 2006a, 2008). In nitrogenlimited environments, only nutrient additions containing nitrogen consistently yield an increase in phytoplankton chlorophyll a biomass. A small physiological response can accompany this change in biomass (Fig. 8). However, the observed response is not the same as would be predicted on the basis of culture data, indicating an increase in $F_{\mathrm{v}} / F_{\mathrm{m}}$ on relief of nitrogen starvation (Geider et al. 1993b). Typically, values of $F_{\mathrm{v}} / F_{\mathrm{m}}$ decrease by ca. 10 to $15 \%$, whilst values of $\sigma_{\text {PSII }}(478)$ increase by ca. 15 to $20 \%$ (e.g. Fig. 8) following relief from $\mathrm{N}$-limitation. One potential explanation may involve preferential synthesis of phycobilisomes leading to decreased $F_{\mathrm{v}} / F_{\mathrm{m}}$ due to an artifactually high $F_{\mathrm{o}}$ as explained above, but only if cyanobacteria dominated the physiological response. Similar low physiological sensitivity (sometimes accompanied by a decrease in $F_{\mathrm{v}} / F_{\mathrm{m}}$ of $<50 \%$; Behrenfeld et al. 2006) following release from N-limitation has also been ob- 

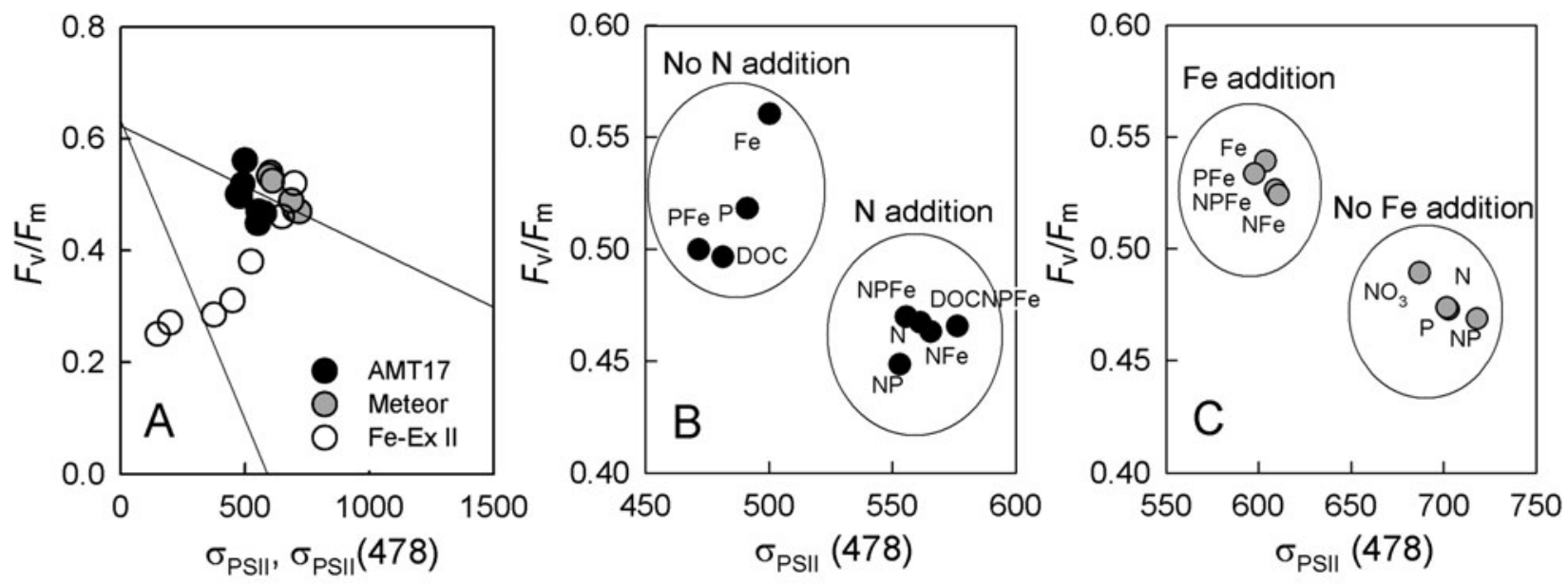

Fig. 8. Values of maximum PSII photochemical efficiency $\left(F_{\mathrm{v}} / F_{\mathrm{m}}\right.$, dimensionless) and effective absorption cross section $\left(\sigma_{\mathrm{PSII}} \AA^{2}\right.$ quanta $^{-1}$ ) plotted for: (A) the IronEx II in situ fertilisation experiment (Behrenfeld et al. 1996; our Table 2), and $F_{\mathrm{V}} / F_{\mathrm{m}}$ and $\sigma_{\mathrm{PSII}}$ (478) for on-deck nutrient addition incubation experiments during: (B) AMT 17, $23^{\circ} \mathrm{S}, 17^{\circ} \mathrm{W}$, November 2005 (Suggett \& Moore unpubl. data) and (C) METEOR 60, $42^{\circ} \mathrm{N}, 42^{\circ} \mathrm{W}$, April 2004, (Moore et al. 2006a). Phycobilisome and chlorophyll-xanthophyll LHC 'trajectories' determined for regressions applied to laboratory culture data from Fig. 2 are overlaid; data from the nutrientaddition experiments have been rescaled (Panels B, C) to more clearly illustrate the small but significant effects of different nutrient treatments: $+\mathrm{N}_{1}+\mathrm{P}_{1}+\mathrm{Fe}_{1}+\mathrm{NP},+\mathrm{NFe}_{1}+\mathrm{PFe}_{1}+\mathrm{NPFe},+\mathrm{NO}_{3}$, dissolved organic carbon (DOC) combinations (note the initial and control have been removed for clarity). Each data point is the mean of triplicate incubations for each treatment. Two data clusters appear for both the AMT 17 and METEOR 60 experiments: these correspond to: (B) one for $+\mathrm{N}$ (low $F_{\mathrm{v}} / F_{\mathrm{m}}$, high $\sigma_{\mathrm{PSII}}(478)$ ) and $-\mathrm{N}$ (high $F_{\mathrm{v}} / F_{\mathrm{m}}$, low $\sigma_{\mathrm{PSII}}(478)$ ) for AMT17, and $(\mathrm{C})+\mathrm{Fe}\left(\right.$ high $F_{\mathrm{v}} / F_{\mathrm{m},}$ low $\sigma_{\mathrm{PSII}}(478)$ ) and $-\mathrm{Fe}\left(\right.$ low $F_{\mathrm{v}} / F_{\mathrm{m}}$, high $\sigma_{\mathrm{PSII}}(478)$ ) for METEOR 60

served in the sub-tropical Pacific (Behrenfeld et al. 2006) and in a high biomass subtropical estuary (Juhl \& Murrell 2008).

Nutrient-limited communities thus appear to yield a FRR fluorescence signal that is indicative of a physiological response in many cases. However, the direction of change can vary between environments, and the extent of change of both $F_{\mathrm{V}} / F_{\mathrm{m}}$ and $\sigma_{\mathrm{PSII}}$ in response to nutrient addition (Fig. 8) is frequently small compared to differences between taxa (Fig. 2A). Together, these data sets imply that across non-HNLC regions much of the variability in $F_{\mathrm{v}} / F_{\mathrm{m}}$ and $\sigma_{\mathrm{PSII}}(478)$ can be accounted for by taxonomic gradients (Fig. 6). Lack of sensitivity of $F_{\mathrm{v}} / F_{\mathrm{m}}$ to limiting macro-nutrient amendment (Graziano et al. 1996, Behrenfeld et al. 2006, Moore et al. 2008) also suggests that nutrient starvation may be rare in these systems. Much of the open ocean may thus potentially be in balanced nutrient-limited growth, with the resident phytoplankton communities physiologically acclimated to nutrient limitation and potentially experiencing environmental variability of either low frequency or magnitude (Moore et al. 2008). Under such a scenario, significant physiologically driven variability of $F_{\mathrm{v}} / F_{\mathrm{m}}$ and $\sigma_{\mathrm{PSII}}$ might only be expected where steady-state conditions break down, for example, during transient nutrient-enrichment events (e.g. Falkowski et al. 1991), which cause a proportion of the community structure to experience rapid growth followed by nutrient starvation.

\section{Interpreting future FRR measurements}

FRR fluorometry has gained popularity in oceanographic studies as a means to provide a rapid assessment of phytoplankton physiology. Since its introduction, $F_{\mathrm{v}} / F_{\mathrm{m}}$ (and to a lesser extent $\sigma_{\mathrm{PSII}}$ ) has frequently been used as an unambiguous diagnostic of nutrient limitation, e.g. (Kolber et al. 1988, 1994, Geider et al. 1993a, Behrenfeld et al. 1996). However, as we have highlighted here, signals generated by FRR fluorescence are the product of a complex mix of acclimation, inhibition and adaptative processes. Based on the wide variability of FRR fluorescence characteristics observed for marine phytoplankton grown in culture, as well as the many consistent features observed in FRR fluorescence data sets collected across ocean regions, it is apparent that FRR fluorescence measurements in situ can exhibit a strong taxonomic (adaptive) component. Furthermore, the short-term stress components of fluorescence-based measurements of photosynthetic physiology appear to decrease as phytoplankton acclimate over longer periods to nutrient limitation in culture (Parkhill et al. 2001, Cullen et al. 1992, Price 2005). Such acclimation to nutrient limitation may be analogous to growth conditions in some low-nutrient, open-ocean regions (Marañon 2005, Moore et al. 2008). Together, these observations clearly demonstrate that using FRR fluorescence parameters to explicitly characterise (stress) physiology 
comes with a caveat: observations of $F_{\mathrm{v}} / F_{\mathrm{m}}$ and $\sigma_{\mathrm{PSII}}$ will inevitably consist of a physiological signal superimposed upon a taxonomic signal. In many cases, taxonomic gradients, as well as steady-state acclimation to long-term nutrient limitation, may thus override any effect of direct physiological stress.

Any interpretation of FRR fluorescence measurements must certainly account for changes in the community structure; in particular, if we are to improve the confidence with which FRR fluorometry accurately gauges the (eco-) physiological response of aquatic systems to environmental change. To date, a key use of FRR-based measurements of $F_{\mathrm{v}} / F_{\mathrm{m}}$ and $\sigma_{\mathrm{PSII}}$ has been the estimation of PSII electron transport, and, hence, following a variety of assumptions (conversion factors), overall phytoplankton community photosynthesis in situ (Kolber \& Falkowski 1993, Kromkamp \& Forster 2003, Suggett et al. 2003, Smyth et al. 2004). Detailed discussion of the influence that the taxonomic variability described herein will have within these models is beyond the scope of the current manuscript and will be considered elsewhere. However, of key importance is that any algorithm that relies on a taxon-independent 'typical' or 'constant' value for either $F_{\mathrm{v}} / F_{\mathrm{m}}$ or $\sigma_{\mathrm{PSII}}$ may ultimately be susceptible to errors.

Increasing availability of FRR data for key taxa under controlled growth environments will no doubt continue to aid the interpretation of field data; however, broad-scale environmental assessments should consider more substantial truthing of FRR 'signatures' for key species that are specific to the system under consideration. One suggestion for future FRR fluorometry would, therefore, be a movement towards multisensor bio-optical platforms that take advantage of the recent technological advances in instrumentation for examining microalgal community structure, for example, multi-spectral radiometers and/or submersible flow cytometers, alongside these physiological measurements.

Observations of taxonomic variability inherent to FRR-based measurements are derived from instruments tuned to detect fluorescence following excitation of a specific (narrow) waveband, hence, the difficulties in reconciling observations using a Fast ${ }^{\text {tracka }}$ versus a custom-built FRR fluorometer, for example. Taxonomic variability in fluorescence-based parameters simply reflects differences in antenna size, arrangement and functioning for this region of the photosynthetically active spectrum. Consequently, interpretation of observed patterns is likely to be improved by a move towards multi-spectral FRR fluorometers. The advantages are potentially 2 -fold, with a means not only to examine changes in taxonomy according to bulk fluorescence yields but also to generate values of $F_{\mathrm{v}} / F_{\mathrm{m}}$ and $\sigma_{\mathrm{PSII}}$ that are closer to those that might be expected under 'natural' light fields. Either way, better resolution of the spectral dependence of the fluorescence-based description of phytoplankton physiology will generate much novel information on algal types and their response to environmental change.

Finally, we stress again that, in addition to shortterm physiological stress responses, changes in bulk community ecophysiology resulting from taxonomic shifts also convey important information on system responses to environmental forcing. The taxonomic traits of different phytoplankton groups/sizes, including the variable fluorescence yield and the effective absorption cross section of PSII, will have experienced considerable evolutionary pressure. Consequently, the fundamental differences in PSII characteristics which we have discussed likely contribute significantly to phytoplankton biogeography in the modern ocean.

Acknowledgements. The authors thank Ilana Berman-Frank (Bar Ilan University, Israel), Mika Raateoja (Finnish Institute of Marine Research), Ondřej Prášil (Institute of Microbiology, Trebon), Pedro Cermeño and Patricia Estévez-Blanco (University of Vigo, Spain) for their extremely generous contributions of previously unpublished FRR fluorescence data. We also thank Hugh MacIntyre, whose continued input and encouragement through discussion over the past few years have been an inspiration. As ever, we owe a debt of gratitude to John Cullen and 2 additional anonymous reviewers for providing insightful comments to further improve this manuscript. This work was funded through UK National Environmental Research Council (NERC) postdoctoral fellowships to D.J.S. and C.M.M., through NERC Grants NER/A/S/2000/ 01237 and MARQUEST NE/C516087/01, a NERC studentship (A.E.H.) and the CARBOOCEAN integrated project (European Commission Contract No. 511176). The present study was also supported by NERC through the Atlantic Meridional Transect consortium (NER/O/S/2001/00680) and is Contribution Number 176 of the AMT programme.

\section{LITERATURE CITED}

Aiken J, Fishwick J, Moore G, Pemberton K (2004) The annual cycle of phytoplankton photosynthetic quantum efficiency, pigment composition and optical properties in the western English Channel. J Mar Biol Assoc UK 84: 301-313

Behrenfeld MJ, Kolber ZS (1999) Widespread iron limitation of phytoplankton in the south Pacific Ocean. Science 283: 840-843

Behrenfeld MJ, Bale AJ, Kolber ZS, Aiken J, Falkowski PG (1996) Confirmation of iron limitation of phytoplankton photosynthesis in the equatorial Pacific Ocean. Nature 383:508-511

Behrenfeld MJ, Worthington K, Sherrell RM, Chavez FP, Strutton P, McPhaden M, Shea DM (2006) Controls on tropical Pacific Ocean productivity revealed through nutrient stress diagnostics. Nature 442:1025-1028

Berman-Frank I, Quigg A, Finkel ZV, Irwin AJ, Haramaty L 
(2007) Nitrogen-fixation strategies and Fe requirements in cyanobacteria. Limnol Oceanogr 52:2260-2269

Berner T, Wyman KW, Falkowski PG (1989) Photoadaptation and the package effect in Dunaliella tertiolecta (Chlorophyceae). J Phycol 25:70-78

Bibby T, Nield J, Barber J (2001) Iron-stress induces the formation of an antenna ring around trimeric Photosystem I in cyanobacteria. Nature 412:743-745

Bibby TS, Gorbunov MY, Wyman KW, Falkowski PG (2008) Photosynthetic community responses to upwelling in mesoscale eddies in the subtropical North Atlantic and Pacific Oceans. Deep-Sea Res II 55:1310-1320

Boyd PW, Abraham ER (2001) Iron-mediated changes in phytoplankton photosynthetic competence during SOIREE. Deep-Sea Res II 48:2529-2550

Bruyant F, Babin M, Genty B, Prášil O and others (2005) Diel variations in the photosynthetic parameters of Prochlorococcus strain PCC 9511: combined effects of light and cell cycle. Limnol Oceanogr 50:850-863

Campbell D, Hurry V, Clarke AK, Gustafsson P, Gunnar Ö (1998) Chlorophyll fluorescence analysis of cyanobacterial photosynthesis and acclimation. Microbiol Mol Biol Rev 62:667-683

Cermeño $\mathrm{P}$, Estévez-Blanco $\mathrm{P}$, Marañón E, Fernández E (2005) Maximum photosynthetic efficiency of size-fractionated phytoplankton assessed by ${ }^{14} \mathrm{C}$-uptake and fast repetition rate fluorometry. Limnol Oceanogr 50:1438-1446

Cullen JJ, Davis RF (2003) The blank can make a big difference in oceanographic measurements. Limnol Oceanogr Bull 12:29-35

Cullen JJ, Yang X, MacIntyre HL (1992) Nutrient limitation and marine photosynthesis. In: Falkowski PG, Woodhead AD (eds) Primary productivity and biogeochemical cycles in the sea. Plenum Press, New York, p 69-88

> Duyens LMN (1956) The flattening effect of the absorption spectra of suspensions as compared to that of solutions. Biochim Biophys Acta 19:1-12

Falkowski PG, Oliver MJ (2007) Mix and match: how climate selects phytoplankton. Nat Rev Microbiol 5:813-819

Falkowski PG, Raven JA (2007) Aquatic photosynthesis, 2nd edn. Princeton University Press, Princeton, NJ

Falkowski PG, Ziemann D, Kolber ZS, Bienfang PK (1991) Role of eddy pumping in enhancing primary production in the ocean. Nature 352:55-58

Falkowski PG, Greene RM, Geider RJ (1992) Physiological limitations on phytoplankton productivity in the ocean. Oceanography (Wash DC) 5:84-91

Finkel ZV (2001) Light absorption and the size scaling of light-limited growth and photosynthesis in marine diatoms. Limnol Oceanogr 46:86-94

Finkel ZV, Sebbo J, Feist-Burkhardt S, Irwin AJ and others (2007) A universal driver of macroevolutionary change in the size of marine phytoplankton over the Cenozoic. Proc Natl Acad Sci USA 104:20416-20420

> Fishwick JR, Aiken J, Barlow R, Sessions H, Bernard S, Ras J (2006) Functional relationships and bio-optical properties derived from phytoplankton pigments, optical and photosynthetic parameters; a case study of the Benguela ecosystem. J Mar Biol Assoc UK 86:1267-1280

Geider RJ, Platt T, Raven JA (1986) Size dependence of growth and photosynthesis in diatoms: a synthesis. Mar Ecol Prog Ser 30:93-109

Geider RJ, Greene RM, Kolber ZS, MacIntyre H, Falkowski PG (1993a) Fluorescence assessment of the maximum quantum efficiency of photosynthesis in the western North Atlantic. Deep-Sea Res 40:1205-1224

Geider RJ, LaRoche J, Greene RM, Olaizola M (1993b)
Response of the photosynthetic apparatus of Phaeodactylum tricornutum (Baccilariophyceae) to nitrate, phosphate or iron starvation. J Phycol 29:755-766

Gervais F, Riebesell U, Gorbunov MY (2002) Changes in primary productivity and chlorophyll $a$ in response to iron fertilization in the Southern Polar Frontal Zone. Limnol Oceanogr 47:1324-1335

Glover HE, Keller MD, Spinrad RW (1987) The effects of light quality and intensity on photosynthesis and growth of marine eukaryotic and prokaryotic phytoplankton clones. J Exp Mar Biol Ecol 105:137-159

> Goldman JC, McCarthy JJ, Peavey DG (1979) Growth rate influence on the chemical composition of phytoplankton in oceanic waters. Nature 279:210-215

> Graziano LM, La Roche J, Geider RJ (1996) Physiological responses to phosphorous limitation in batch and steady state cultures of Dunaliella tertiolecta (Chlorophyta): a unique stress protein as an indicator of phosphate deficiency. J Phycol 32:825-838

> Greene RM, Geider RJ, Kolber Z, Falkowski PG (1992) Iron induced changes in light harvesting and photochemical energy conversion processes in eukaryotic marine-algae. Plant Physiol 100:565-575

Greene RM, Kolber ZS, Swift DG, Tindale NW, Falkowski PG (1994) Physiological limitation of phytoplankton photosynthesis in the eastern equatorial Pacific determined from variability in the quantum yield of fluorescence. Limnol Oceanogr 39:1061-1074

Herzig R, Falkowski PG (1989) Nitrogen limitation in Isochrysis galbana. 1. Photosynthetic energy conversion and growth efficiencies. J Phycol 25:462-471

Irwin AJ, Finkel ZV, Schofield OME, Falkowski PG (2006) Scaling-up from nutrient physiology to the size-structure of phytoplankton communities. J Plankton Res 28:459-471

Johnsen G, Sakshaug E (2007) Biooptical characteristics of PSII and PSI in 33 species (13 pigment groups) of marine phytoplankton, and the relevance for pulse amplitude modulated and fast repetition rate fluorometry. J Phycol 43:1236-1251

Juhl AR, Murrell MC (2008) Nutrient limitation of phytoplankton growth and physiology in a subtropical estuary (Pensacola Bay, Florida). Bull Mar Sci 82:59-82

Kirchhoff H (2008) Significance of protein crowding, order and mobility for photosynthetic membrane functions. Biochem Soc Trans 36:967-970

Koblí̌ek M, Kaftan D, Nedbal L (2001) On the relationship between the non-photochemical quenching of the chlorophyll fluorescence and the Photosystem II light harvesting efficiency. A repetitive flash fluorescence induction study. Photosynth Res 68:141-152

Kolber ZS, Falkowski PG (1993) Use of active fluorescence to estimate phytoplankton photosynthesis in situ. Limnol Oceanogr 38:1646-1665

Kolber ZS, Zehr J, Falkowski PG (1988) Effects of growth irradiance and nitrogen limitation on photosynthetic energy conversion in Photosystem II. Plant Physiol 88:923-929

Kolber ZS, Wyman KD, Falkowski PG (1990) Natural variability in photosynthetic energy conversion efficiency: a field study in the Gulf of Maine. Limnol Oceanogr 35:72-79

Kolber ZS, Barber RT, Coale KH, Fitzwater SE and others (1994) Iron limitation of phytoplankton photosynthesis in the equatorial Pacific Ocean. Nature 371:145-146

Kolber ZS, Prášil O, Falkowski PG (1998) Measurements of variable chlorophyll fluorescence using fast repetition rate techniques: defining methodology and experimental protocols. Biochim Biophys Acta 1367:88-106

Kromkamp JC, Forster RM (2003) The use of variable fluores- 
cence measurements in aquatic ecosystems: differences between multiple and single turnover measuring protocols and suggested terminology. Eur J Phycol 38:103-112

Laney SR, Letelier RM (2008) Artifacts in measurements of chlorophyll fluorescence transients, with specific application to fast repetition rate fluorometry. Limnol Oceanogr Methods 6:40-50

Lavergne J, Joliot P (2000) Thermodynamics of the excited states of photosynthesis. In: Cramer WA (ed) Biophysics textbook onLine. Biophysical Society, Bethesda, MD, p 1-12

Leonardos N, Geider RJ (2004) Responses of elemental and biochemical composition of Chaetoceros muelleri to growth under varying light and nitrate: phosphate supply ratios and their influence on critical N:P. Limnol Oceanogr 49:2105-2114

Lutz VA, Sathyendranath S, Head EJH, Li WKW (2001) Changes in the in vivo absorption and fluorescence excitation spectra with growth irradiance in three species of phytoplankton. J Plankton Res 23:555-569

MacIntyre HL, Kana TM, Anning T, Geider RJ (2002) Photoacclimation of photosynthesis irradiance response curves and photosynthetic pigments in microalgae and cyanobacteria. J Phycol 38:17-38

Marañon E (2005) Phytoplankton growth rates in the Atlantic subtropical gyres. Limnol Oceanogr 50:299-310

Mauzerall D, Greenbaum NL (1989) The absolute size of a photosynthetic unit. Biochim Biophys Acta 974:119-140

Moore CM, Lucas MI, Sanders R, Davidson R (2005) Basinscale variability of phytoplankton bio-optical characteristics in relation to bloom state and community structure in the Northeast Atlantic. Deep-Sea Res I 52:401-419

Moore CM, Mills MM, Milne A, Langlois R and others (2006a) Iron supply limits primary productivity during spring bloom development in the central North Atlantic. Glob Change Biol 12:626-634

Moore CM, Suggett DJ, Hickman AE, Kim YN and others (2006b) Phytoplankton photoacclimation and photoadaptation in response to environmental gradients in a shelf sea. Limnol Oceanogr 51:936-949

> Moore CM, Seeyave S, Hickman AE, Allen JT and others (2007) Iron-light interactions during the CROZet natural iron bloom and EXport experiment (CROZEX). I. Phytoplankton growth and photophysiology. Deep-Sea Res II 54:2045-2065

Moore CM, Mills MM, Langlois R, Milne A, Achterberg EP, La Roche J, Geider RJ (2008) Relative influence of nitrogen and phosphorus availability on phytoplankton physiology and productivity in the oligotrophic sub-tropical North Atlantic Ocean. Limnol Oceanogr 53:291-305

Morel A, Bricaud A (1981) Theoretical results concerning light absorption in a discrete medium, and application to specific absorption of phytoplankton. Deep-Sea Res 28: 1375-1393

Olson RJ, Sosik HM, Chekalyuk AM, Shalapyonok A (2000) Effects of iron enrichment on phytoplankton in the Southern Ocean during late summer: active fluorescence and flow cytometric analyses. Deep-Sea Res II 47:3181-3200

Parkhill JP, Maillet G, Cullen JJ (2001) Fluorescence-based maximal quantum yield for PSII as a diagnostic of nutrient stress. J Phycol 37:517-529

Partensky F, La Roche J, Wyman K, Falkowski PG (1997) The divinyl-chlorophyll $a / b$-protein complexes of two strains of the oxyphototrophic marine prokaryote Prochlorococcuscharacterization and response to changes in growth irradiance. Photosynth Res 51:209-222

Penno S, Campbell L, Hess WR (2000) Presence of phycoery- thrin from two strains of Prochlorococcus (Cyanobacteria) isolated from the subtropical North Pacific Ocean. J Phycol 36:723-729

Prášil O, Suggett DJ, Cullen JJ, Babin M, Govindjee (2008) Aquafluo 2007: chlorophyll fluorescence in aquatic sciences, an international conference held in Nove Hrady. Photosynth Res 95:111-115

Price NM (2005) The elemental stoichiometry and composition of an iron-limited diatom. Limnol Oceanogr 50: $1159-1171$

Raateoja M, Seppälä J, Ylöstalo P (2004) Fast repetition rate fluorometry is not applicable to studies of filamentous cyanobacteria from the Baltic Sea. Limnol Oceanogr 49: 1006-1012

Ragni M, Airs R, Leonardos N, Archer S, Geider RJ (2008) Photoinhibition of PSII in Emiliania huxleyi (Haptophyta) under high light stress: the roles of photoacclimation, photoprotection and photorepair. J Phycol 44:670-683

Raven JA (1986) Physiological correlates of extremely small size for autotrophic organisms in the sea. In: Platt $\mathrm{T}, \mathrm{Li}$ WKW (eds) Photosynthetic picoplankton. Can Bull Fish Aquat Sci 214:1-70

Raven JA (1999) The size of cells and organisms in relation to the evolution of embryophytes. Plant Biol 1:2-12

Six C, Finkel ZV, Rodriguez F, Marie D, Partensky F, Campbell DA (2008) Contrasting photoacclimation costs in ecotypes of the marine eukaryotic picoplankter Ostreococcus. Limnol Oceanogr 53:255-265

Smyth TJ, Pemberton KL, Aiken J, Geider RJ (2004) A methodology to determine primary production and phytoplankton photosynthetic parameters from fast repetition rate fluorometry. J Plankton Res 26:1337-1350

Sosik HM, Olson RJ (2002) Phytoplankton and iron limitation of photosynthetic efficiency in the Southern Ocean during late summer. Deep-Sea Res I Oceanogr Res Pap 49: 1195-1216

Steglich C, Behrenfled M, Koblížek M, Claustre C and others (2001) Nitrogen deprivation strongly affects Photosystem II but not phycoerythrin level in the divinyl-chlorophyll b-containing cyanobacterium Prochlorococcus marinus. Biochim Biophys Acta 1503:341-349

Stomp M, Huisman J, Voros L, Pick FR, Laamanen M, Haverkamp T, Stal LJ (2007) Colourful coexistence of red and green picocyanobacteria in lakes and seas. Ecol Lett 10:290-298

Strzepek RF, Harrison PJ (2004) Photosynthetic architecture differs in coastal and oceanic diatoms. Nature 431:689-692

Suggett DJ, Oxborough K, Baker NR, MacIntyre HL, Kana TM, Geider RJ (2003) Fast repetition rate and pulse amplitude modulation chlorophyll a fluorescence measurements for assessment of photosynthetic electron transport in marine phytoplankton. Eur J Phycol 38:371-384

Suggett DJ, MacIntyre HL, Geider RJ (2004) Evaluation of biophysical and optical determinations of light absorption by photosystem II in phytoplankton. Limnol Oceanogr Methods 2:316-332

Suggett DJ, Maberly SC, Geider RJ (2006a) Gross photosynthesis and lake community metabolism during the spring phytoplankton bloom. Limnol Oceanogr 51:2064-2076

Suggett DJ, Moore CM, Marañón E, Omachi C, Varela RA, Aiken J, Holligan PM (2006b) Photosynthetic electron turnover in the tropical and subtropical Atlantic Ocean. Deep-Sea Res II 53:1573-1592

> Suggett DJ, Le Floc HE, Harris GN, Leonardos N, Geider RJ (2007) Different strategies of photoacclimation by two strains of Emilinia huxleyi (Haptophyta). J Phycol 43: $1209-1222$ 
Suggett DJ, Warner ME, Smith DJ, Davey P, Hennige SJ, Baker NR (2008) Photosynthesis and production of hydrogen peroxide by Symbiodinium (Pyrrhophyta) phylotypes with different thermal tolerances. J Phycol 44:948-956

Suzuki K, Liu H, Saino T, Obata H and others (2002) East-West gradients in the photosynthetic potential of phytoplankton and iron concentration in the subarctic Pacific Ocean during early summer. Limnol Oceanogr 47: 1581-1594

Vaillancourt RD, Sambrotto RN, Green S, Matsuda A (2003) Phytoplankton biomass and photosynthetic competency in the summertime Mertz Glacier Region of East Antarctica. Deep-Sea Res II 50:1415-1440

Editorial responsibility: Graham Savidge, Portaferry, UK
Vassiliev IR, Prasil O, Wyman KD, Kolber ZK, Hanson AK, Prentice JE, Falkowski PG (1994) Inhibition of PS II photochemistry by PAR and UV radiation in natural phytoplankton communities. Photosynth Res 42:51-64

Vassiliev IR, Kolber ZK, Wyman KD, Mauzerall D, Shukla VK, Falkowski PG (1995) Effects of iron limitation on photosystem-ii composition and light utilization in Dunaliella tertiolecta. Plant Physiol 109:963-972

$>$ Wood AM (1985) Adaptation of photosynthetic apparatus of marine ultraplankton to natural light fields. Nature 316: 253-255

Yentsch CS, Yentsch CM, Phinne DA, Lapointe BE, Yentsch SFW (2004) The odyssey of new production. J Exp Mar Biol Ecol 300:15-30

Submitted: January 13, 2008; Accepted: November 14, 2008 Proofs received from author(s): January 22, 2009 